\title{
GE POL DIAMONDS: BEFORE AND AFTER
}

\author{
By Christopher P. Smith, George Bosshart, Johann Ponahlo, Vera M. F. Hammer, \\ Helmut Klapper, and Karl Schmetzer
}

This study of type IIa GE POL diamonds before and after HPHT annealing by GE significantly expands on their characterization. The color change was dramatic: from the $\mathrm{N}-\mathrm{O}$ range through Fancy Light brown before, to $D-H$ after. However, there was little change to the inclusions, graining, and strain as a result of HPHT exposure. Photoluminescence (PL) studies — conducted at liquid helium, liquid nitrogen, and room temperatures in the 245-700 nm range-identified a significant reconfiguration of the lattice involving substitutional impurities, vacancies, and interstitials. Key regions of $P L$ activity included the areas of the N3, H3, and $\mathrm{N}-\mathrm{V}$ centers. $X$-ray topography identified the extent of lattice distortion. Cathodoluminescence may help establish that a diamond is not HPHT annealed. A distinction between nonenhanced and color-enhanced type IIa diamonds can be made through a combination of observations and features.

\section{ABOUT THE AUTHORS}

Mr. Smith is director, and Mr. Bosshart is chief gemologist, at the Gübelin Gem Lab, Lucerne, Switzerland. Dr. Ponahlo is senior research scientist, and Dr. Hammer is research scientist, in the mineralogy and petrography department at the Museum of Natural History, Vienna, Austria. Prof. Klapper is the head of the crystal growth research group at the Mineralogisch-Petrographisches Institut, University of Bonn, Germany. Dr. Schmetzer is a research scientist residing in Petershausen, near Munich, Germany.

Please see acknowledgments at the end of the article.

Gems \& Gemology, Vol. 36, No. 3, pp. 192-215 (C) 2000 Gemological Institute of America

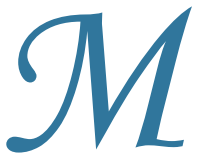

arch 1, 1999 is a watershed date in the gem and jewelry trade. This is when General Electric (GE) and Lazare Kaplan International (LKI) unveiled their latest contribution to the diamond and jewelry industry: diamonds that had undergone a new GE process "designed to improve their color, brilliance, and brightness" (Rapnet, 1999). Colloquially, these diamonds became known as "GE POL" or "Pegasus" diamonds, because they were being marketed through LKI subsidiary Pegasus Overseas Ltd. (POL). At the July 2000 Jewelers of America trade show in New York, however, the brand name Bellataire was officially launched.

The first gemological description of GE POL diamonds appeared in fall 1999, when GIA published an overview of the macroscopic and microscopic features observed in $858 \mathrm{GE}$ POL diamonds they had examined up to August 1999 (Moses et al., 1999). Subsequent articles by the SSEF Swiss Gemmological Institute and De Beers provided more analytical details on GE POL diamonds and suggested spectroscopic methods of identification (Chalain et al., 1999, 2000; Fisher and Spits, 2000). The Gübelin Gem Lab (GGL) has had an ongoing cooperation with GE, LKI, and POCL (Pegasus Overseas Company Ltd.) to investigate the gemological and analytical characteristics of GE POL diamonds, in order to help develop identification criteria. Because of this collaboration, staff members at GGL were given the opportunity to document a selection of diamonds taken from current GE production, both prior and subsequent to high pressure/high temperature (HPHT) processing (figure 1).

This study represents the first independent investigation of actual GE POL diamonds both before and after processing by General Electric. Such an investigation is crucial to understanding the mechanisms behind the color alteration and thus to providing greater insight into potential methods of identification. The present report not only addresses the alterations in color, inclusions, graining, and strain produced by the GE process, but it also considerably expands the 

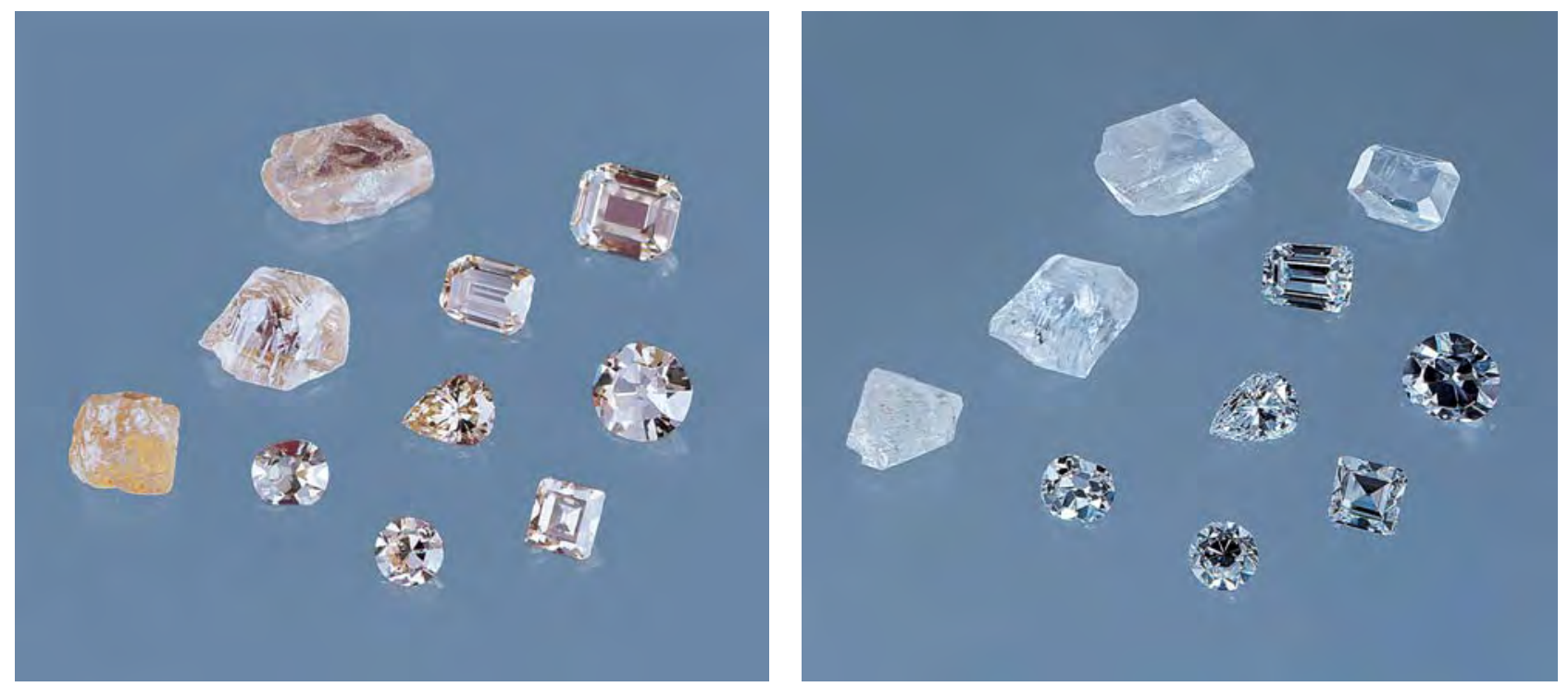

Figure 1. These two illustrations show 10 of the study samples before and after HPHT processing. The brown type IIa diamonds on the left received color grades from the N-O range to Fancy Light brown (C3-C5 on the Argyle scale). Following processing by GE, the color improved dramatically, with the diamonds on the right grading from $D$ to $H$. The seven faceted samples weigh 0.48 to $2.72 \mathrm{ct}$, and the three pieces of rough weigh 2.32 to $3.71 \mathrm{ct}$. Photos by Phillip Hitz.

analytical characterization of GE POL diamonds using photoluminescence data acquired with laserRaman systems, cathodoluminescence, and X-ray topography. Since brown coloration in type IIa diamonds is associated with plastic deformation of the crystal lattice (Wilks and Wilks, 1991), these advanced analytical techniques were selected to pay particular attention to defect centers, trace impurities, and structural distortion, in order to document the changes that may be taking place in the lattice. For more information on these atomic-level diamond features, the reader is referred to box $\mathrm{A}$.

\section{MATERIALS AND METHODS}

Samples. We studied seven faceted stones and three crystals that were selected at random from POCL's stock of brown type Ila diamonds (see, e.g., figure 1). The faceted diamonds ranged from 0.48 to $2.72 \mathrm{ct}$. The three crystals weighed 2.32 to $3.71 \mathrm{ct}$; we had windows polished on two of them to permit viewing of their interiors. GE, LKI, and POCL independently confirmed that no pre-processing of the diamonds had taken place. As a "control" sample, a $0.61 \mathrm{ct}$ type IIa brown pear shape was selected from the Gübelin Gem Lab's reference collection and submitted to GE for HPHT processing. All 11 samples were subjected to the tests described below both before and after HPHT processing by General Electric. The precise conditions used by GE are proprietary, and were not revealed to the authors. Of these 11 samples, six (including the one GGL sample) were selected as representative to show the range of properties and characteristics exhibited by the larger group (table 1).

In the course of grading at GGL, and as part of ongoing research, we have had the opportunity to test many natural, nonprocessed, near-colorless type IIa diamonds and GE POL diamonds by the methods listed below. Our preliminary results for these diamonds are incorporated into the Discussion and Applications sections below.

The Risk Factor. When diamonds (and other gems) are exposed to elevated temperatures and pressures, there is always the risk of thermal shock extending existing fractures or creating new ones. As a graphic reminder of this, two of the 11 samples inexplicably broke in the course of HPHT processing. The 1.92 ct octagonal step cut cleaved along an octahedral plane (111), shearing the stone in two parallel to the table facet; a secondary fracturing took away one corner (refer to the after photo of GE4 in table 1). The 1.22 ct round (GE3) had to be considerably reformed because a small section chipped. This damage occurred in both diamonds even though there were no fractures or other inclusions, significant slip traces, or twinning present prior to enhancement. It is interesting that none of the three diamonds that had fractures experienced any damage during HPHT processing. 


\section{BOX A: UNDERSTANDING VACANCIES, INTERSTITIALS, AND COLOR CENTERS}

Many of the features discussed in this article are related to point defects (e.g., vacancies, interstitials, and substitutional impurities) present at the atomic level in the lattice of a diamond. Figures A-1 to A-3 offer a simplified, two-dimensional illustration of the major defect centers discussed in this article, which relate to HPHT processing of type IIa diamonds.

These three figures are drawn after diagrams provided by the De Beers Diamond Trading Center.

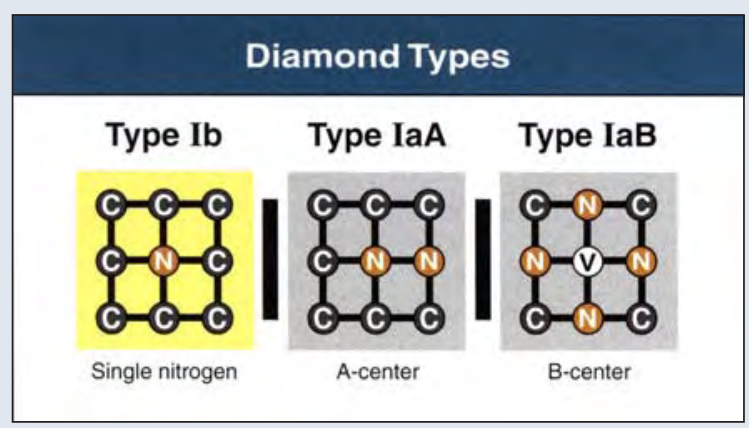

Figure A-1. These schematic diagrams illustrate the occurrence of substitutional impurities in different diamond types; each produces distinctive spectral features in the infrared region and is detectable with IR spectroscopy. In type Ib diamonds, a carbon atom is substituted by a single nitrogen atom. In type Ia diamonds, substitutional nitrogen atoms are aggregated. The most common diamond types are IaA (which have a pair of nitrogen atoms, the $A$ aggregate) and IaB (in which four nitrogen atoms surround a common vacancy, the B aggregate). Those rare diamonds that are classified as type IIa do not show nitrogen (or boron) impurities in their IR spectra.
Nitrogen-Vacancy Defect Centers

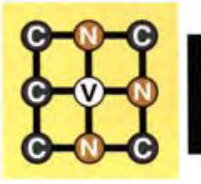

$3 \mathrm{~N}-\mathrm{V}$ (N3)

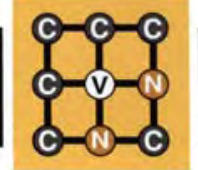

$\mathrm{N}-\mathrm{V}-\mathrm{N}(\mathrm{H} 3, \mathrm{H} 2)$

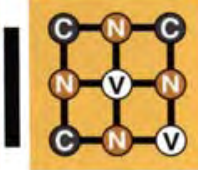

$4 \mathrm{~N}-2 \mathrm{~V}(\mathrm{H} 4)$
Figure A-2. Diamonds may also contain additional defect centers, which involve the combination of substitutional nitrogen impurities and vacancies. These include the N3 system (three nitrogen atoms surrounding a vacancy), the $\mathrm{H3}$ and H2 systems (an A-aggregate associated with a vacancy[uncharged and negatively charged, respectively]), and the $\mathrm{H} 4$ system (a B-aggregate bound to an additional vacancy).

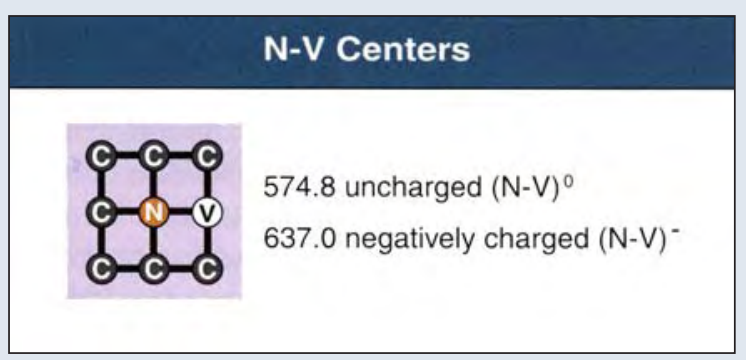

Figure A-3. Illustrated here are the two types of nitrogen-vacancy $(N-V)$ centers (uncharged and negatively charged), where a single nitrogen atom is attached to a single vacancy.
Gemological Examination and UV-Vis-NIR and IR Testing. Color observations were made in the neutral environment of a MacBeth Judge II light box. Colorimetric measurements were carried out with a Zeiss multichannel color spectrometer (MCS 311). Clarity assessments and the study of internal characteristics such as inclusions and graining were carried out with a binocular microscope and various lighting techniques. We used crossed polarizing filters to observe the internal strain patterns and interference colors.
We performed absorption spectroscopy in the ultraviolet (UV), visible (Vis), and near-infrared (NIR) regions of the spectrum $(200-2500 \mathrm{~nm})$ with a Perkin-Elmer Lambda 19 spectrometer. We recorded the spectra with the diamonds at both room and liquid nitrogen temperatures; the slit width provided a spectral resolution of $0.2 \mathrm{~nm}$, and the data interval was $0.2 \mathrm{~nm}$.

Mid- and near-infrared absorption spectra were taken at room temperature with a Philips 9624 Fourier-transform infrared (FTIR) spectrometer in the 
When a type IIa diamond is exposed to HPHT nditions, the lattice of the diamond goes through a process of reconfiguration. That is, within the lattice, some of the point defects present prior to $\mathrm{HPHT}$ processing - such as $\mathrm{N}-\mathrm{V}, \mathrm{H} 4$, and $\mathrm{H} 3$ centers and nitrogen aggregates - are broken up. In addition, vacancies and nitrogen impurities will mobilize; vacancies and interstitials may mutually annihilate; and N3 centers are created, as is single substitutional nitrogen.

\section{Definition of Frequently Used Terms}

Vacancy-An unoccupied carbon site within the crystal lattice of a diamond.

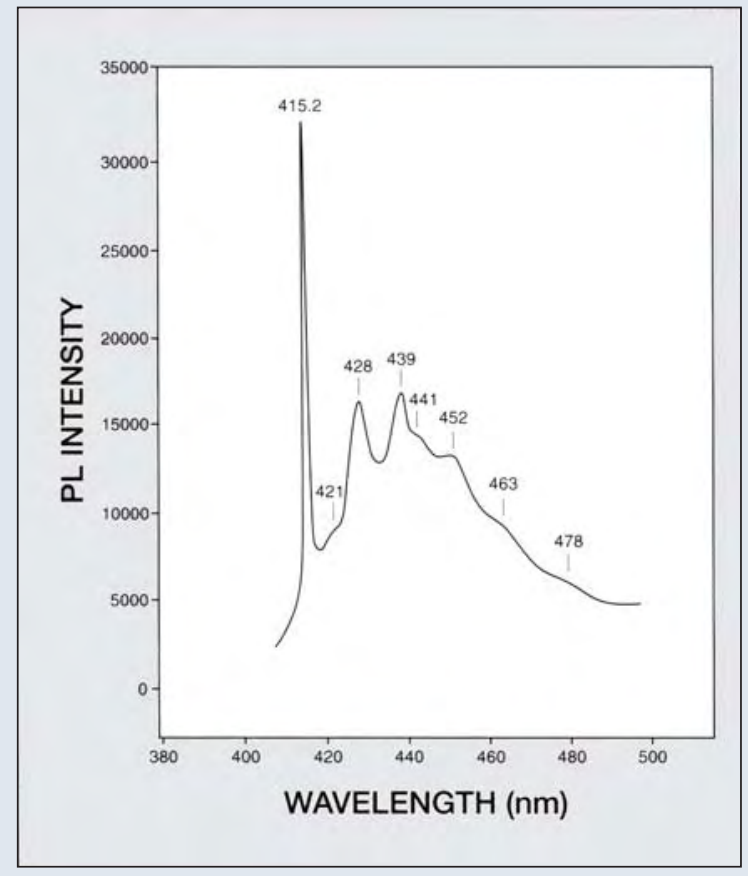

Interstitial-Any carbon or impurity atom (nitrogen, hydrogen, or boron) that does not occupy a carbon site in the lattice of the diamond, but is situated in a space between regular carbon sites.

Color center-Any point defect (also generally referred to as a defect center) inside the lattice that absorbs visible light and thereby imparts color to the diamond. Examples are vacancies and substitutional impurities (e.g., nitrogen occupying a carbon site). Note that A and $\mathrm{B}$ aggregates of nitrogen absorb infrared light only; because they do not absorb in the visible region of the spectrum, they are not color centers.

Photoluminescence Systems. Some point defects luminesce when excited by UV radiation or visible light. This photoluminescence (PL) appears as peaks or bands, some of which represent PL systems, such as N3 or H3. All PL systems behave in a similar fashion, with a zero-phonon line generated by an electronic transition and side bands (also referred to as phonon replicas) caused by acoustic transitions in the form of lattice vibrations (i.e., characteristic vibrations of molecules and crystals), as illustrated in figure A-4. Such PL systems may be likened to a stone dropped in water, where the zero-phonon line is the point at which the stone enters the water and the side bands are the ripples that emanate from this point.

Figure A-4. In a PL system such as the N3 illustrated here), $\mathrm{H} 3$, or $(\mathrm{N}-\mathrm{V})^{-}$, the zero-phonon line (here, the 415.2) is accompanied by a number of side bands. These phonon replicas make up a series of progressively weaker and broader bands at higher wavelengths, which combine to form a structured band with an underlying emission maximum at a characteristic wavelength, such as at approximately $440 \mathrm{~nm}$ (N3), $520 \mathrm{~nm}$ (H3), and $680 \mathrm{~nm}(\mathrm{~N}-\mathrm{V})^{-}$. range of 7000 to 400 wavenumbers $\left(\mathrm{cm}^{-1}\right)$, with a standard $4 \mathrm{~cm}^{-1}$ resolution; we used a SpectraTech diffuse reflectance collector for the faceted samples and a Specac $5 \times$ beam condenser for the rough specimens.

Other Advanced Testing. Photoluminescence, cathodoluminescence, and X-ray topography are not standard analytical techniques in most gemological laboratories. However, researchers have applied these techniques to the study of diamonds in order to characterize various types of lattice defects (see, e.g., Wild and Evans, 1967; Woods and Lang, 1975; Lang and Moore, 1991; Collins, 1992, 1996; Davies, 1999). Photoluminescence (PL) was well described in basic terms by Fisher and Spits (2000, p. 44). Note that a laser is used to study PL features because of its efficient excitation of impurities and defect centers, even when they are present in very low concentrations. Because the photoluminescence of diamonds is a fluorescence behavior, stones may react differently when exposed to various wavelengths. Therefore, the use of lasers with different excitations (i.e., 244 and 
TABLE 1. Gemological and other properties before and after HPHT processing for five GE diamonds and one Gübelin Gem Lab reference sample. ${ }^{a}$

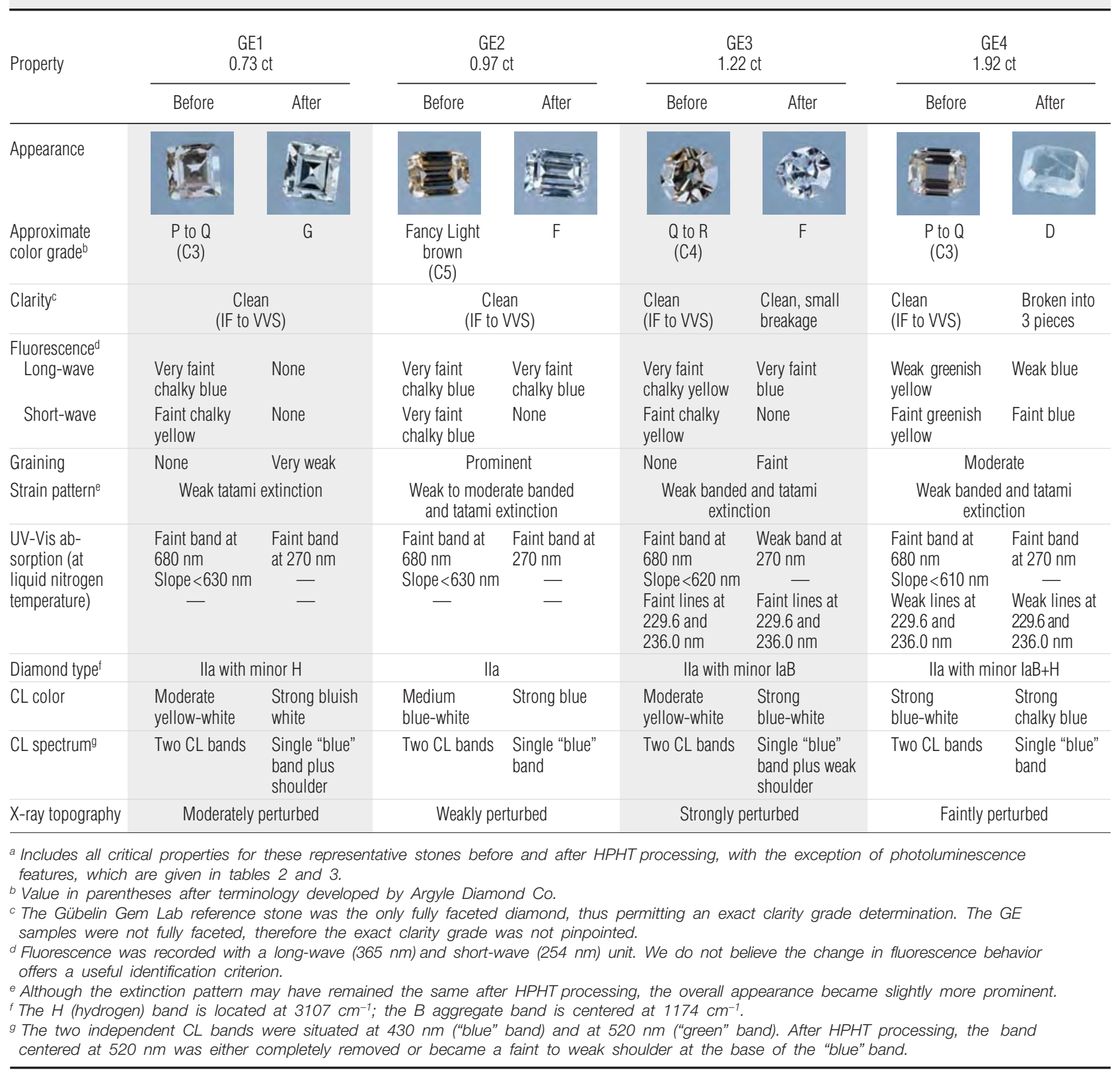

$325 \mathrm{~nm}$ in the UV, $488 \mathrm{~nm}$ in the blue, and 514 or 532 in the green regions of the spectrum) may show varying results. For example, the $637 \mathrm{~nm}$ system is not excited by the $325 \mathrm{~nm}$ " $U V^{\prime}$ " laser and is excited less efficiently by the $488 \mathrm{~nm}$ "blue" laser, as compared to the 514 or $532 \mathrm{~nm}$ "green" lasers.

Low-temperature conditions are necessary to properly resolve all of the PL features that may be present (Fisher and Spits, 2000). However, we have also included the results of our analyses at room temperature, because these spectra may help confirm that a high-color type IIa diamond has not been enhanced by HPHT processing.

Photoluminescence spectra were recorded with laser Raman microspectrometers over the range $245-700 \mathrm{~nm}$. For the UV region from 245 to $700 \mathrm{~nm}$, we used a Renishaw System 1000 equipped with a frequency-doubled Argon-ion laser (excitation wavelength at $244 \mathrm{~nm}$ ). To cover the $325-700 \mathrm{~nm}$ range, we used a Dilor LabRam Infinity and a Renishaw System 1000, each equipped with a helium/cadmium $(\mathrm{He} / \mathrm{Cd}$ ) laser (excitation at $324.98 \mathrm{~nm})$. To focus on the region between 550 and $700 \mathrm{~nm}$, we used a Dilor LabRam Infinity equipped with a frequency- 


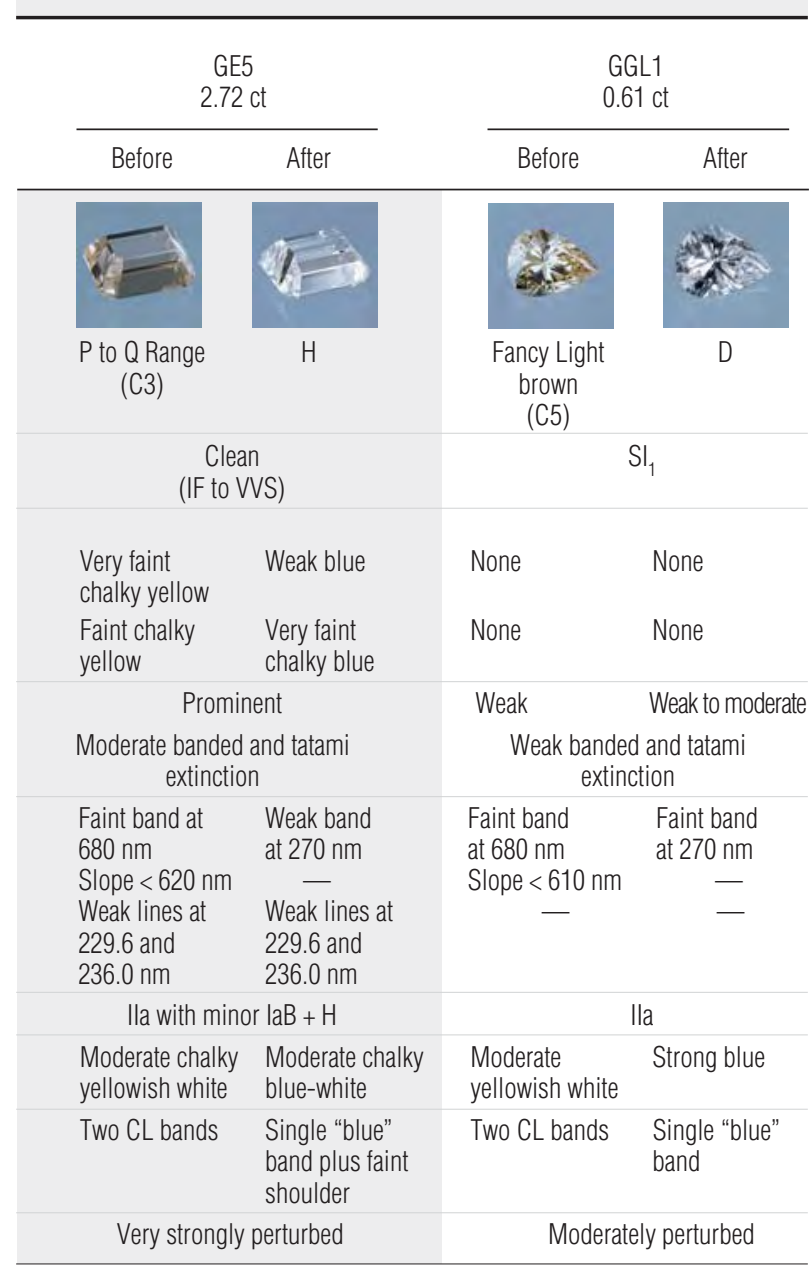

doubled Nd/YAG laser (excitation at $531.78 \mathrm{~nm}$ ), as well as a Renishaw System 1000 equipped with an Argon-ion laser providing excitation at $514.5 \mathrm{~nm}$. We used both the Dilor and Renishaw Raman systems to rule out instrumental artifacts. Both systems produced equivalent results of very high spectral resolution. The diamonds were analyzed at temperatures near those of liquid helium $\left(-263^{\circ} \mathrm{C} / 10 \mathrm{~K}\right)$ and liquid nitrogen $\left(-196^{\circ} \mathrm{C} / 77 \mathrm{~K}\right)$ and at room temperature (approximately $25^{\circ} \mathrm{C} / 298 \mathrm{~K}$ ) using a THMS 600 heating and cooling stage manufactured by Linkam Scientific Industries Ltd.

We also performed cathodoluminescence (CL) analyses over the range $380-700 \mathrm{~nm}$ using flood gun optical CL microscopy ("cold CL"; see Box B). For this technique, we used a Zeiss microscope and a Luminoscope with a large sample compartment, which also permitted visual observation of the CL colors and phosphorescence effects. For the spectral analyses, we used a monochromator slit width that provided a resolution of $5 \mathrm{~nm}$. The monochromator sits on top of the microscope and is coupled by optical lenses. The image is then focused on the entrance of the slit of the monochromator to obtain optimal intensity. The acceleration voltage of the electron beam was $4.5 \mathrm{kV}$ with a current of $0.5 \mathrm{~mA}$. Beam energy was kept constant throughout all the tests by pressure regulation of the current, which carried ionized gas (air). Scanning CL microscopy ("hot $\mathrm{CL}^{\prime}$ ) in the region 200-700 $\mathrm{nm}$ was carried out with an Oxford Instruments MonoCL system, with a stepscan of $1 \mathrm{~nm}$, attached to a JEOL JSM 6400 SEM-EDS instrument, operating at an accelerating voltage of 15 $\mathrm{kV}$ and a beam current of approximately $1 \mathrm{~mA}$.

$\mathrm{X}$-ray topography was performed with a Seifert ISO-Debyeflex 1001 generator using a molybdenum fine focus W2000 Philips X-ray tube. Operation conditions were $50 \mathrm{kV}$ and $25 \mathrm{~mA}$, with a slit beam (white-beam section topography in Laue forwardreflection arrangement). The fine-grained AGFAGevaert Structurix D4 film used required exposure times of approximately 12 hours per sample. Using the Laue technique with white X-ray light, no special orientation of the samples was necessary.

\section{RESULTS: GEMOLOGICAL OBSERVATIONS AND UV-VIS-NIR AND INFRARED SPECTROSCOPY}

The properties for all of the samples before and after HPHT processing are discussed below. The specific results for five of the GE stones and the one GGL sample are listed in table 1. For the most part, these six samples encompassed all of the features seen in the larger group.

\section{Color Appearance}

Before: All 11 samples in this study were originally light to medium brown (figure 1, left; table 1). The GIA color grade equivalents extended from approximately the $\mathrm{N}$ to $\mathrm{O}$ range through Fancy Light brown. Applying the common diamond trade terminology developed by the Argyle Diamond Co. for their "champagne" diamonds, we estimated their colors to range from $\mathrm{C} 3$ to $\mathrm{C} 5$ (on a $\mathrm{C} 1$ to $\mathrm{C} 10$ scale, ranging from pale to extremely dark brown). It is important to note that this group may not represent the full range of colors that are processed by GE.

Colorimetric measurements showed that the original hues (i.e., dominant wavelengths) were located in a narrow range between 578.8 and 580.4 $\mathrm{nm}$. These wavelengths correspond to the yellow to orange-yellow region of the visible spectrum. The measured color saturation ranged from $15.8 \%$ to 

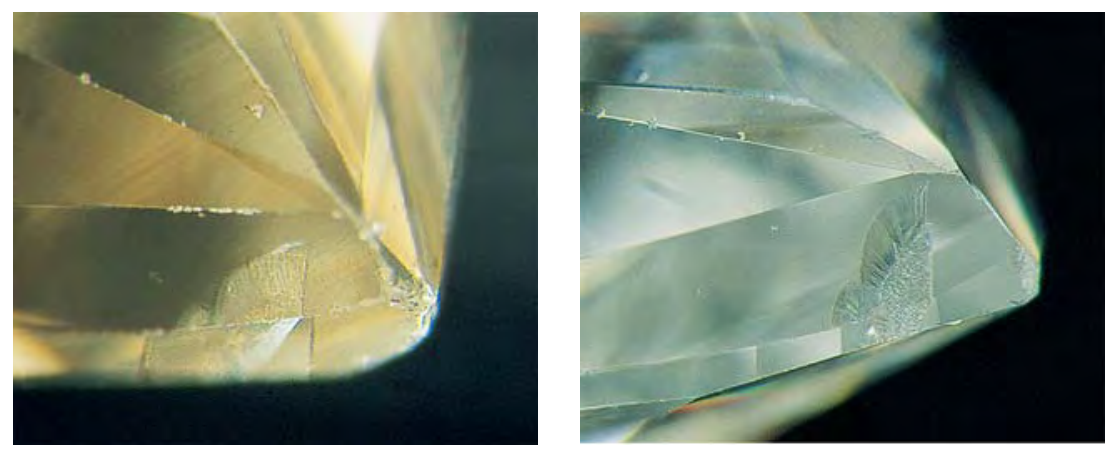

Figure 2. Before processing (left), this fracture in the $0.61 \mathrm{ct}$ GGL sample was bright and reflective. After HPHT processing (right), the area of the original fracture had acquired $a$ coarse (frosted) texture and we noticed the addition of a bright transparent extension, or "fringe." No graphitization was observed. Photomicrographs by Christopher P. Smith; magnified 55x.

$25.4 \%$ (on a 0 to $100 \%$ scale). The tones varied between 2.7 and 4.1 (on a 0 to 10 scale). The ratios of tone and saturation extended from 0.14 to 0.21 (for objective color evaluation, GGL uses a T/S ratio to standardize the description of brown and gray in colored diamonds), corresponding to low or moderate saturations and light to medium tones. The data obtained for this color study are influenced by geometry and surface conditions and therefore may show some variation from one sample to the next.

After: All samples were dramatically enhanced by HPHT processing (figure 1, right). Most were in the colorless range of $\mathrm{D}$ to $\mathrm{F}$. One sample retained a slight brownish color and was graded as $\mathrm{H}$ on the GIA color-grading scale.

We measured a substantial decrease in saturation and tone, as well as a slight shift in hue, in the processed diamonds. The modified colors varied from 570.6 to $576.4 \mathrm{~nm}$ in hue, from $0.8 \%$ to $5.2 \%$ in saturation, and from 0.5 to 3.0 in tone. These data correspond to an average shift of $-5.4 \mathrm{~nm}$ in hue, $-18 \%$ in saturation, and -1.5 in tone from the original, light brown colors. With these data, we can better understand why GE POL diamonds appear yellow, rather than brown, at colors lower than $\mathrm{H}$ on the GIA grading scale (refer to diamonds described in Moses et al., 1999; Fisher and Spits, 2000). For the human eye, this is a very sensitive region of the visible spectrum; even a shift of only a few nanometers and a decrease in tone can make the previously brown diamonds appear yellow.

\section{Clarity and Inclusions}

Before: Few of the samples contained observable mineral inclusions or fractures. LKI informed us that in their experience, brown type IIa diamond rough is commonly very clean (P. Kaplan, pers. comm., 2000). Two of the POCL samples did contain small fractures. The GGL sample had a tiny crystal with a small, brightly reflective stress halo, as well as two small fractures (see, e.g., figure 2, left) and a natural. Although we did not clarity grade the GE POL diamonds, because only the GGL sample was fully faceted, we determined that the clarity grades would be VVS or better.

After: Re-examination of these diamond inclusions

Figure 3. One sample $(2.72 \mathrm{ct}$ ) showed significant whitish graining with a "cottony" texture before HPHT processing (left). After processing (right), the fundamental character of the graining had not changed, although it appeared to be slightly more prominent. Such prominent graining imparted an overall haziness to the diamond both before and after enhancement. This diamond also showed the greatest degree of lattice distortion on the $X$-ray topographs. Photomicrographs by Christopher P. Smith; magnified 14×.
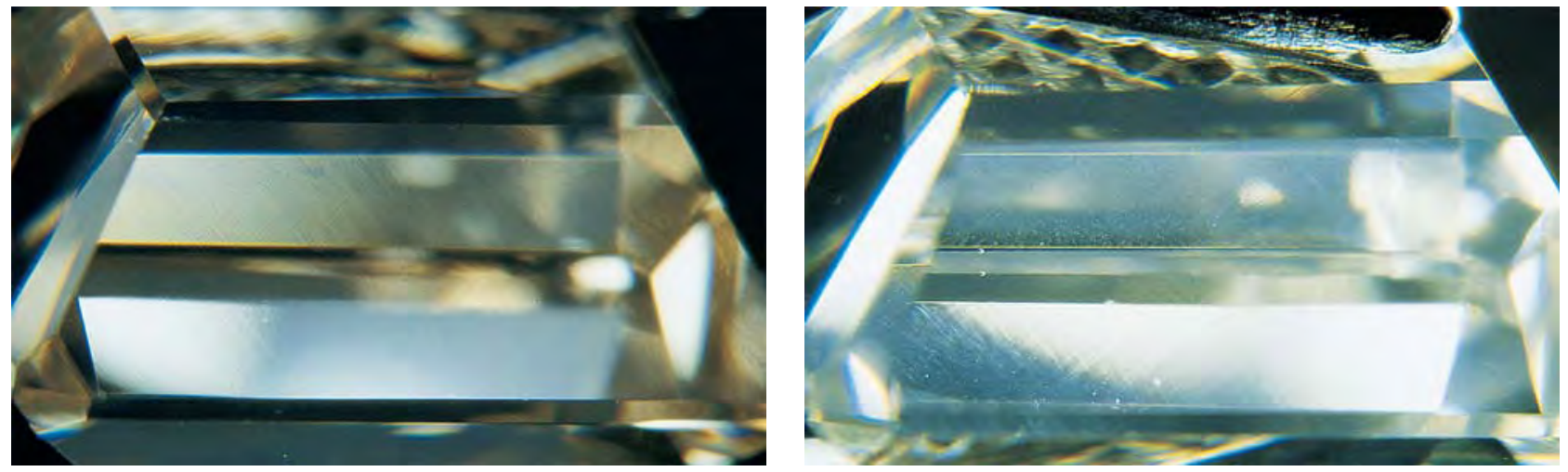

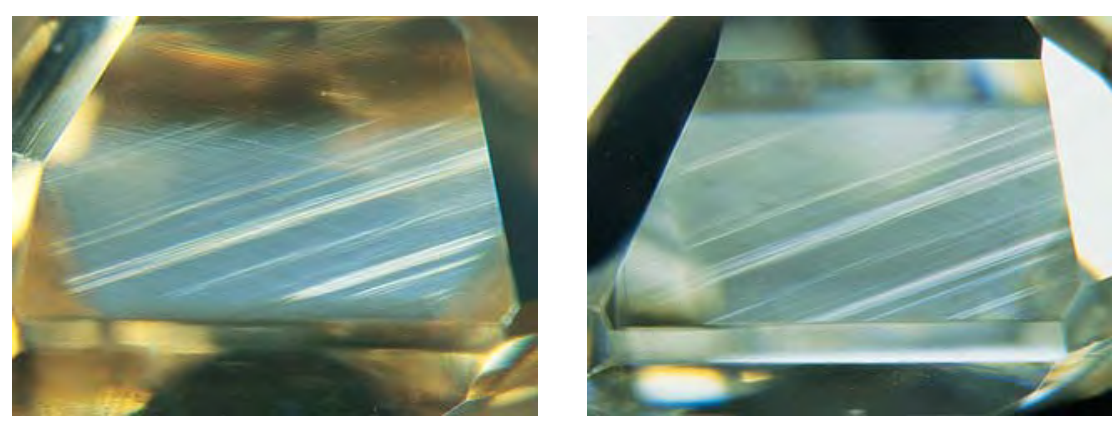

Figure 4. Sample GE 2 (0.97 ct) displayed prominent slip bands (also referred to as whitish or silvery graining). There was no apparent alteration in these bands as a result of HPHT processing (left, before; right, after). Photomicrographs by Christopher P. Smith; magnified 30x.

after processing revealed little change as a result of exposure to HPHT conditions. The appearance of the open fractures had altered slightly in some cases, where the fracture walls became textured or frosted as a result of partial dissolution; in other cases, some degree of extension was evident in the creation of an outer "fringe" (see, e.g., figure 2, right). The bright stress fracture in the GGL sample healed in the region immediately surrounding the crystal; yet we observed no healing along the further extension of the stress fracture. The changes observed did not have a significant effect on the clarity grades.

\section{Graining}

Before: We did not observe any internal graining in four of the eight faceted samples. The other samples displayed internal graining that ranged from very weak to prominent. In one specimen, the very fine texture of the graining generated a faint overall "sheen" in the stone when it was viewed with darkfield illumination. One sample with prominent (i.e., whitish) graining displayed a distinctly "cottony" texture (figure 3, left). Another sample had significant graining in a linear formation along slip traces (figure 4, left).

After: Although the texture of the graining remained unchanged (figure 4, right) in all samples, the graining itself did appear just slightly more prominent in most (figure 3, right). Overall, however, we did not observe a dramatic alteration (figure 4, right).

\section{Strain Patterns}

Before: Anomalous birefringence (caused by strain in the crystal lattice) was noted in all the specimens when they were viewed between crossed polarizers. As is typical of type IIa diamonds, the samples revealed weak to moderate banded and crosshatched (tatami) extinction patterns, with first-order interference colors of gray and violet to blue, which extended to yellow and orange within patches in two samples (figure 5). In a direction parallel to octahedral crystal faces in one sample, we saw a moderate banded strain pattern with weak firstorder interference colors (figure 6, left).

After: Overall we did not observe dramatic modifications to the strain patterns after HPHT processing. However, with close inspection we were able to note some subtle changes: Although the actual patterns (i.e., banded and tatami) remained the same, they were very slightly more prominent after processing; the first-order interference colors were also slightly augmented (figure 6, right).

\section{UV-Vis-NIR Absorption Spectroscopy}

Before: The spectra of all the samples were remarkably uniform throughout the UV-Vis-NIR range. No absorption bands were observed in the near-infrared $(700-2500 \mathrm{~nm})$ region. Only faint bands were detected below $700 \mathrm{~nm}$ : N9 lines at 229.6 and 236.0 $\mathrm{nm}$ in the UV region of three samples (figure 7 and table 1). Wide, yet faint bands were also detected around 480, 560, and $680 \mathrm{~nm}$ in the visible region (the first two discernable only in the MCS spectra), but they were too weak to have any obvious

Figure 5. As is typical for type IIa diamonds, all of the samples studied showed tatami and banded extinction patterns with first-order interference colors when viewed between crossed polarizers. Photomicrograph by Christopher P. Smith; magnified 14×.

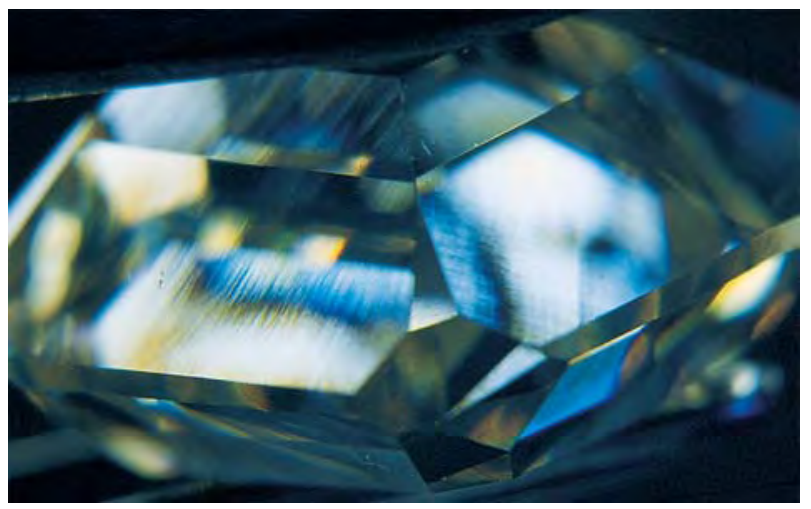



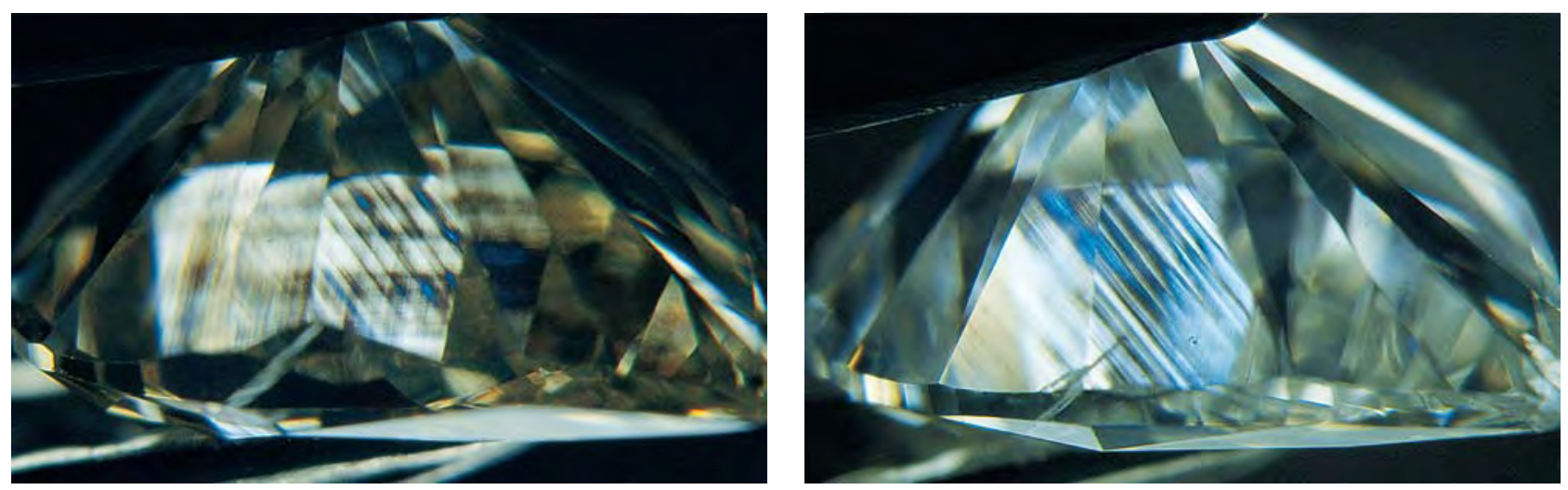

Figure 6. Prior to HPHT processing (left), we observed a banded strain pattern parallel to octahedral growth planes that showed primarily weak (gray) interference colors when viewed between crossed polarizers. After processing (right), the overall pattern remained the same, but the first-order interference colors were slightly stronger (bluer). Note that such strain patterns and interference colors may also be seen in non-enhanced colorless type IIa diamonds. Photomicrographs by Christopher P. Smith; magnified 20×.

influence on the bodycolor. In all specimens, the gradual absorption slope (or "continuum") started at approximately $620 \mathrm{~nm}$ and became steeper toward $400 \mathrm{~nm}$, causing the light brown color. The absorption curve continued to climb in the UV region toward the fundamental absorption edge of diamond at $225 \mathrm{~nm}$.

After: There was a significant decrease in the absorption continuum, as well as an overall reduction in the general absorption level. In particular, the slope became very subtle in the visible region and the bands that were barely detectable disappeared. This explains the nearly or completely colorless appearance of the specimens after exposure to HPHT conditions.

However, we also noted that a new, broad, faintto-weak absorption band had developed in all samples, centered at approximately $270 \mathrm{~nm}$. In the three samples with a trace of $B$ aggregates, this band was accompanied by faint-to-weak absorption lines at the base of the absorption edge-at 229.6, 236.0, and (in one sample only) at 227.4, 243.1, and $249.6 \mathrm{nm-}$ which were unchanged by HPHT processing.

\section{Infrared Spectroscopy}

The mid-infrared spectrum of a chemically pure diamond is characterized by the two-phonon and three-phonon absorption bands (2650-1500 and $4000-2650 \mathrm{~cm}^{-1}$, respectively). These features are intrinsic to diamond. The infrared classification of diamond types is based on absorption bands related to nitrogen $(\mathrm{N})$ in the one-phonon region, between 1500 and $1000 \mathrm{~cm}^{-1}$ (see, e.g., Fritsch and Scarratt, 1992). It also has been long understood that this was a qualitative as opposed to a quantitative clas- sification, so that nitrogen and other impurities may still be detected in type IIa diamonds with high-resolution and/or high-sensitivity techniques.

Before: All 11 samples were classified as type IIa, based on the relative absence of IR features in the one-phonon region under typical testing conditions (figure 8 and table 1). By expanding this region however, we noted that some of the samples displayed a weak, broad band at approximately $1174 \mathrm{~cm}^{-1}$, which corresponds to nitrogen in the form of $\mathrm{B}$ aggregates. In addition, we recorded a small sharp peak at $3107 \mathrm{~cm}^{-1}$, which identifies traces of hydrogen impurities. Only two of the samples did not show any detectable traces of chemical impurities (nitrogen, hydrogen, or boron).

After: It is interesting that none of the samples revealed any apparent increase or decrease in the nitrogen aggregate or hydrogen contents. Furthermore, as observed with our testing conditions, it appears that no IR absorption bands were either annihilated or generated by the GE process.

\section{RESULTS: PHOTOLUMINESCENCE SPECTROSCOPY}

Tables 2 and 3 list all the PL features recorded under room- and low-temperature conditions, respectively, before and after HPHT processing. When evaluating more than one spectrum from a single sample or from multiple samples, it is possible to normalize the spectra by comparing the intensity of the diamond's Raman signal. Note that as part of their own independent research, GE has used photoluminescence to characterize synthetic diamonds both before and after HPHT 


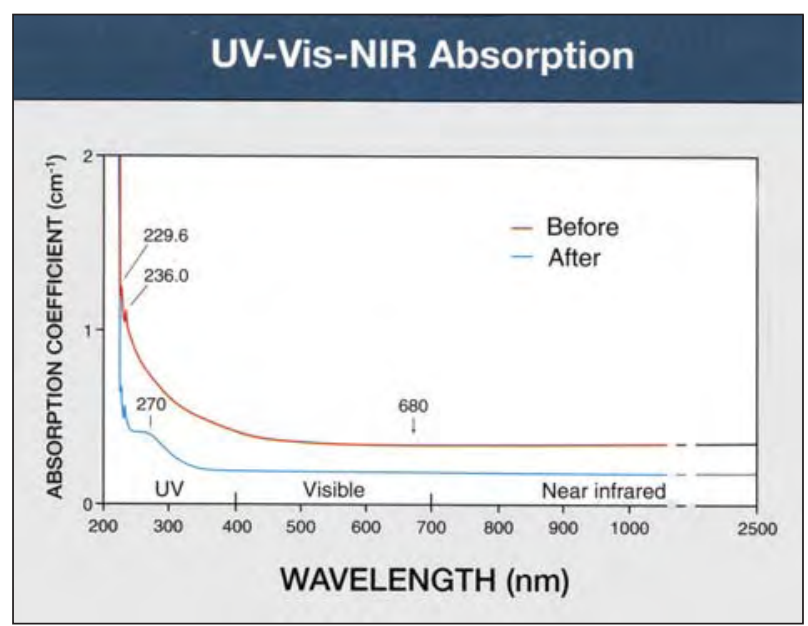

Figure 7. These UV/Vis/NIR absorption spectra of the $2.72 \mathrm{ct}$ sample (GE5), recorded at liquid nitrogen temperature and high resolution, illustrate the absorption characteristics of a GE POL diamond before and after HPHT processing. The light brown ( $P$ to $Q$ range) type IIa specimen initially exhibited a faint $680 \mathrm{~nm}$ band, an increase in general absorption starting at approximately $620 \mathrm{~nm}$, and the N9 absorption lines at 229.6 and $236.0 \mathrm{~nm}$. In contrast, following HPHT processing, the general absorption of the same sample in the visible region was almost entirely annihilated, which improved the color to an H grade (faint brown). Notably, a broad band centered at about $270 \mathrm{~nm}$ also developed (due to the formation of a small amount of single nitrogen). However, the two N9 lines at the base of the fundamental absorption edge (225 nm), appear to be unaffected. The absorption coefficient indicated is approximate.

application (e.g., Jackson and Webb, 1995; Webb and Jackson, 1995; McCormick et al., 1997).

We listed all the PL features recorded, because the presence of some of these peaks and bands in natural, non-HPHT processed type IIa diamonds may be just as important to the identification procedure as features that suggest HPHT processing. Again, see box A for an illustration of the various nitrogen-impurity forms and point defects that will be discussed.

In all cases, liquid nitrogen temperatures were sufficient to resolve all of the PL features recorded. Liquid helium conditions produced no further refinement of the PL bands present, nor any additional PL bands.

Throughout the text, the authors provide designations for the various PL features that were recorded. There are countless scientific publications which describe these features; however, for ease of

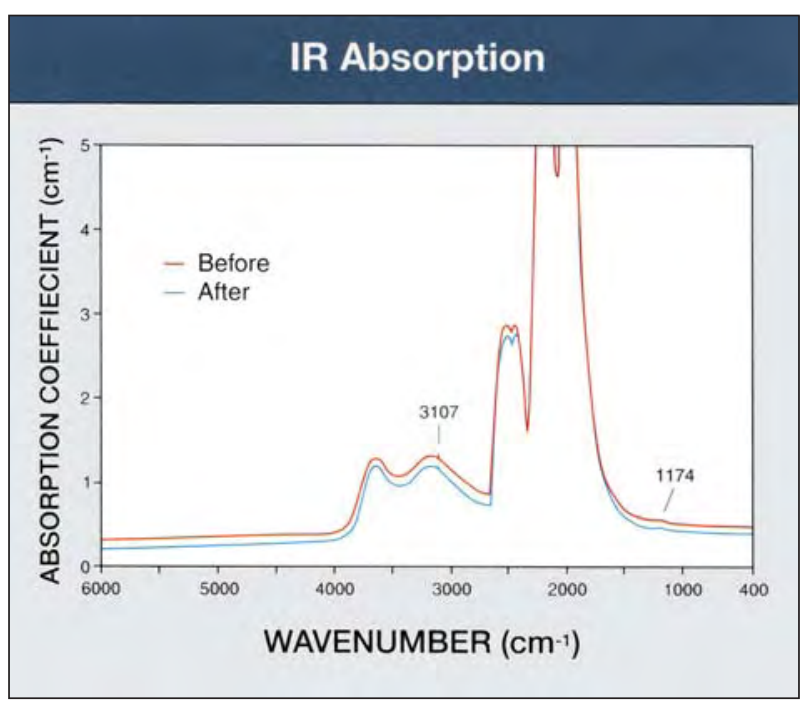

Figure 8. The IR absorption spectra of the GE POL diamond referred to in figure 7 are virtually identical before and after HPHT processing. In particular, the faint hydrogen peak at $3107 \mathrm{~cm}^{-1}$ and the faint band at $1174 \mathrm{~cm}^{-1}$ (attributed to a trace of $B$ aggregates) appear unaltered. The absorption coefficient indicated is approximate.

reference, the authors have used extensively the thorough treatises provided by Davies (1977), Walker (1979), Collins (1982), Woods and Collins (1986), Field (1992), Zaitsev et al. (1996 and 1998), and Iakoubovskii (2000).

[Authors' note: In spectroscopy, the terms peak and band are used synonymously. In this article, however, peak is generally used to represent sharp $P L$ features and band to indicate broader PL features. In addition, all room-temperature PL features are indicated only to the full nanometer (e.g., $503 \mathrm{~nm}$ ), whereas for the low-temperature PL spectra, the sharp peaks are indicated to the tenth of a nanometer (e.g., $503.1 \mathrm{~nm}$ ) and the bands are indicated to the full nanometer (e.g., $680 \mathrm{~nm}$ ). A PL system describes a sharp peak (zero phonon line) that is associated with a series of side bands, all of which relate to a single point defect (e.g., N3 or H3; also refer to box A.]

\section{Frequency-Doubled Ar-Ion Laser (244 nm) Room Temperature}

Before: The dominant features were moderate to weak PL bands at 415 (N3), 256, 257, and $267 \mathrm{~nm}$ (figure 9A). Weak, broad bands were recorded occasionally at approximately 264, 277, 286, and 291 $\mathrm{nm}$. One sample also revealed a faint, sharp peak at $404 \mathrm{~nm}$. 


\begin{tabular}{|c|c|c|c|c|}
\hline $\begin{array}{l}\text { _aser excitation } \\
\text { (nm) }\end{array}$ & $\begin{array}{c}P L \text { feature } \\
(\mathrm{nm})\end{array}$ & $\begin{array}{c}\text { System } \\
\text { assignment }\end{array}$ & Before & After \\
\hline 244 & 256 & & $x$ & $x$ \\
\hline 244 & 257 & & $x$ & $x$ \\
\hline 244 & 264 & & $x$ & \\
\hline 244 & 267 & & $x$ & \\
\hline 244 & 277 & & $x$ & \\
\hline 244 & 286 & & $x$ & \\
\hline 244 & 291 & & $x$ & \\
\hline 244 & 404 & & $x$ & $x$ \\
\hline 325 & 406 & & $\hat{x}$ & \\
\hline 244,325 & 415 & N3 & $x$ & $x$ \\
\hline 325 & 421 & & $x$ & $x$ \\
\hline 325 & 428 & & $x$ & $x$ \\
\hline 325 & 439 & & $x$ & $x$ \\
\hline 325 & 441 & & $x$ & $x$ \\
\hline 325 & 452 & & $x$ & $x$ \\
\hline 325 & 463 & & $x$ & $x$ \\
\hline 325 & 478 & & $x$ & $x$ \\
\hline 325 & 496 & $\mathrm{H} 4$ & $x$ & \\
\hline 325 & 503 & $\mathrm{H} 3$ & $x$ & \\
\hline 325 & 512 & & $x$ & \\
\hline 325 & 520 & & $x$ & \\
\hline 325 & 528 & & $x$ & \\
\hline 325,514 & $537^{b}$ & & $x$ & \\
\hline 514 & 567 & & $x$ & \\
\hline $325,514 / 532$ & $576^{c}$ & $\left(N-V^{0}\right.$ & $x$ & $x$ \\
\hline 325,532 & $579-580$ & & $x$ & \\
\hline 532 & 587 & & $x$ & \\
\hline 532 & 596 & & $x$ & \\
\hline 514 & $613-617$ & & $x$ & \\
\hline $514 / 532$ & 637 & $(\mathrm{~N}-\mathrm{V})^{-}$ & $x$ & $x$ \\
\hline $514 / 532$ & 659 & & $x$ & $x$ \\
\hline $514 / 532$ & 680 & & $x$ & $x$ \\
\hline
\end{tabular}

a Important note: Not all of the PL features noted in this qualitative listing may be present in every diamond. The system designation-e.g., N3, H3, and $(\mathrm{N}-\mathrm{V})^{-}$- is indicated on the zero phonon line. All features in the same system are indicated by the same color.

b The $537 \mathrm{~nm}$ band was resolved into two adjacent peaks at liquid nitrogen temperature (see table 3).

c The $576 \mathrm{~nm}$ band resolved into two adjacent but unrelated peaks at liquid nitrogen temperature.

After: Only the 415 (N3), 256, and 257 nm peaks remained after processing. Under these conditions, all but one sample revealed a general increase in 415 $\mathrm{nm}$ emission. The intensity of the 256 and $257 \mathrm{~nm}$ peaks appeared unchanged.

\section{Low Temperature}

Before: When the samples were cooled, a number of other PL features became evident. The 415.2 (N3) nm peak was dominant, but a number of smaller peaks also were resolved-at 256.2. 257.3, 263.9, 267.3, 277.4, 404.8, 406.0, 412.3, and 417.2 nm (figure 10A).
TABLE 3. Raman photoluminescence features of the diamonds recorded at liquid nitrogen temperature, before and after HPHT processing. ${ }^{\text {a }}$

\begin{tabular}{|c|c|c|c|c|}
\hline $\begin{array}{l}\text { Laser excitation } \\
\qquad(\mathrm{nm})\end{array}$ & $\begin{array}{l}\text { PL feature } \\
(\mathrm{nm})\end{array}$ & $\begin{array}{c}\text { System } \\
\text { assignment }\end{array}$ & Before & After \\
\hline 244 & 251.1 & & $\times$ & \\
\hline 244 & 254.2 & & $x$ & \\
\hline 244 & 256.2 & & $x$ & $\times$ \\
\hline 244 & 257.3 & & $x$ & $x$ \\
\hline 244 & 263.9 & & $x$ & \\
\hline 244 & 265.1 & & $x$ & \\
\hline 244 & 267.3 & & $x$ & \\
\hline 244 & 277.4 & & $x$ & \\
\hline 244 & 286.0 & & $x$ & \\
\hline 244 & 291.6 & & $x$ & \\
\hline 244,325 & 404.8 & & $x$ & $\times$ \\
\hline 244,325 & 406.0 & & $x$ & \\
\hline 325 & 409.6 & & $x$ & $\times$ \\
\hline 325 & 412.3 & & $x$ & $\times$ \\
\hline 244,325 & $415.2^{b}$ & N3 & $x$ & $x$ \\
\hline 244,325 & 417.2 & & $x$ & $x$ \\
\hline 325 & 421 & & $x$ & $x$ \\
\hline 325 & 423.0 & & $x$ & \\
\hline 325 & 428 & & $x$ & $x$ \\
\hline 325 & 430.9 & & & $\times$ \\
\hline 325 & 439 & & $x$ & $x$ \\
\hline 325 & 441 & & $x$ & $\times$ \\
\hline 325 & 452 & & $x$ & $\times$ \\
\hline 325 & 463 & & $x$ & $\times$ \\
\hline 325 & 478 & & $x$ & $x$ \\
\hline 325 & 490.7 & & $x$ & \\
\hline 325 & 496.1 & $\mathrm{H} 4$ & $x$ & \\
\hline 325 & 498.3 & & $\times$ & \\
\hline 325 & 503.1 & $\mathrm{H3}$ & $x$ & $\times$ \\
\hline 325 & 504.9 & & $x$ & \\
\hline 325 & 512 & & $x$ & \\
\hline 325 & 520 & & $x$ & \\
\hline 325 & 528 & & $x$ & \\
\hline 325,514 & 535.9 & & $x$ & \\
\hline 325,514 & 537.4 & & $x$ & \\
\hline 514 & 558.8 & & $x$ & \\
\hline 514 & 566.8 & & $x$ & \\
\hline 514 & 569 & & $x$ & \\
\hline $325,514 / 532$ & $574.8^{c}$ & $(\mathrm{~N}-\mathrm{V})^{0}$ & $\times$ & $\times$ \\
\hline $325,514 / 532$ & 575.8 & $\begin{array}{l}\text { Adjacent unre- } \\
\text { lated peak }\end{array}$ & $\times$ & $\times$ \\
\hline $325,514 / 532$ & 578.8 & & $\times$ & \\
\hline 532 & 587 & & $x$ & \\
\hline 532 & 596 & & $x$ & \\
\hline 514 & 600 & & $x$ & \\
\hline 514 & $613-617$ & & $x$ & \\
\hline 514 & 620 & & $x$ & \\
\hline $514 / 532$ & $637.0^{c, d}$ & $(\mathrm{~N}-\mathrm{V})^{-}$ & $x$ & $\times$ \\
\hline $514 / 532$ & 659 & & $x$ & $x$ \\
\hline $514 / 532$ & 680 & & $x$ & $x$ \\
\hline
\end{tabular}

almportant note: Not all of the PL features noted in this qualitative listing may be present in every diamond. The system designatione.g., N3, $\mathrm{H} 3$, and $(\mathrm{N}-\mathrm{V})^{-}$- is indicated on the zero phonon line. All features in the same system are indicated by the same color. ${ }^{b} 415.2 \mathrm{~nm}$ peak $F W H M=0.38-0.45 \mathrm{~nm}$ (before) and $0.30-0.40$ $\mathrm{nm}$ (after)

${ }^{\circ} 574.8 / 637.0$ ratio $=1.7-7.7$ (before) and 0.3-0.7 (after) ${ }^{d} 637.0 \mathrm{~nm}$ peak $F W H M=0.47-0.80 \mathrm{~nm}$ (before) and $0.64-1.00$ $n m$ (after) 
A couple of samples also revealed peaks at 251.1, 254.2, 265.1, 286.0, 291.6, 407.8, and $409.6 \mathrm{~nm}$.

After: In general, the PL features between 400 and $415 \mathrm{~nm}$ were removed by HPHT processing, except that in two samples the $412.3 \mathrm{~nm}$ peak was reduced to a faint band. Typically, the 415.2 (N3) and 417.2 $\mathrm{nm}$ peaks increased in intensity. All of the PL features below $300 \mathrm{~nm}$ were either less intense or absent altogether.

\section{He/Cd Laser (325 nm) Room Temperature}

Before: The samples revealed two major PL systems, as well as a series of smaller peaks (figure 9B). The primary system is the N3, with its zero-phonon line (ZPL) at $415 \mathrm{~nm}(\mathrm{~N} 3)$ and its associated phonon replicas with peaks at approximately $421,428,439$, 441, 452, 463, and $478 \mathrm{~nm}$ (see box A). The second is the $\mathrm{H} 3$ system, which has its ZPL at $503 \mathrm{~nm}(\mathrm{H} 3)$, with the phonon replicas at approximately 512, 520, and $528 \mathrm{~nm}$. As a result of the broadening of these replicas that occurs at room-temperature conditions, a wide, underlying PL emission was readily visible, with its apex at approximately $520-525 \mathrm{~nm}$. Other PL bands were recorded at 404, 496 (H4), 537, $576(\mathrm{~N}-\mathrm{V})^{0}$, and $580 \mathrm{~nm}$.

After: N3 was the only dominant PL system after processing. There was a general increase in the emission of the N3 system and its ZPL at $415 \mathrm{~nm}$. In two samples, the faint, broad band at $404 \mathrm{~nm}$ was still present. No other PL bands were visible, including the entire $\mathrm{H} 3$ system.

\section{Low Temperature}

Before: At low temperature, the N3 and $\mathrm{H} 3$ systems were sharper and a number of other PL features appeared (figure 10B). In the area of the N3 system, we recorded additional peaks at 406.0, 409.6, 412.3, 417.2 , and $423.0 \mathrm{~nm}$. The width of the $415.2 \mathrm{~nm}$ (N3) line measured at the position of half the peak's height (known as "full width at half maximum" or FWHM) was determined to range from 0.38 to 0.45 $\mathrm{nm}$ (see Fish and Comins, 1997; Fish et al., 1999).

In the area of the $\mathrm{H} 3$ system, all but one of the samples exhibited a $490.7 \mathrm{~nm}$ peak (attributed to defects decorating slip planes; Collins and Woods, 1982). Most also showed a $496.1 \mathrm{~nm}$ (H4) peak, as well as associated peaks at 498.3 and $504.9 \mathrm{~nm}$, which were equal in intensity.

All but one of the samples revealed two adjacent (but unrelated) peaks at 575.8 and $574.8 \mathrm{~nm}(\mathrm{~N}-\mathrm{V})^{0}$, ranging from very weak to moderate, with a relative intensity of $575.8 \geq 574.8$. (At room temperature, these two peaks merged to form the $576 \mathrm{~nm}$ peak.) The variations in relative intensity and band widths recorded during our study are consistent with the findings of Fisher and Spits (2000), which indicate that the $574.8 \mathrm{~nm}(\mathrm{~N}-\mathrm{V})^{0}$ is an independent transition from the $575.8 \mathrm{~nm}$ peak. These PL bands were not present in the GGL sample. The $537 \mathrm{~nm}$ peak recorded at room temperature also resolved into a pair of independent transitions (535.9/537.4 nm); in two of the samples, however, only the $537.4 \mathrm{~nm}$ peak was present. We also recorded a $578.8 \mathrm{~nm}$ peak in all samples.

After: We identified a number of significant changes. Several peaks were removed completely, including the 406.0, 423.0, 490.7, $496.1(\mathrm{H} 4)$ and its related peaks at 498.3 and $504.9 \mathrm{~nm}$; the two at $535.9 / 537.4$ $\mathrm{nm}$; the two at $574.8(\mathrm{~N}-\mathrm{V})^{0}$ and $575.8 \mathrm{~nm}$; and the $580 \mathrm{~nm}$ peak. In addition, the H3 system was either completely removed, or so drastically reduced that only a very small trace of the $503.1 \mathrm{~nm}(\mathrm{H} 3) \mathrm{ZPL}$ was present. The N3 system, however, increased in emission. A small peak at $430.9 \mathrm{~nm}$ was increased or introduced in several samples. There was no apparent modification to the remaining peaks.

The FWHM of the $415.2 \mathrm{~nm}$ (N3) ZPL was 0.30 to $0.40 \mathrm{~nm}$. A slight narrowing of this ZPL was recorded in all samples.

\section{Ar-ion Laser ( $514 \mathrm{~nm}$ ) and Frequency-Doubled Nd/YAG Laser (532 nm) Room Temperature}

Before: We recorded a faint to distinct $576 \mathrm{~nm}$ peak in all but one of the samples, and a weak peak at $579 \mathrm{~nm}$ in all samples (figure 9C). Faint, broad bands were also recorded at $587 \mathrm{~nm}, 596 \mathrm{~nm}$, and approximately $613-617 \mathrm{~nm}$. Another PL feature in this region was the $637 \mathrm{~nm}(\mathrm{~N}-\mathrm{V})^{-}$system. In only four of the samples was the ZPL at $637 \mathrm{~nm}$ present, ranging from faint to moderate. This PL system was accompanied by broad side bands with maxima at approximately 659 and $680 \mathrm{~nm}$.

After: The $576 \mathrm{~nm}$ peak was dramatically reduced in all samples, leaving only traces. In addition, the peaks at 567 and $579 \mathrm{~nm}$, as well as those between 596 and $630 \mathrm{~nm}$, were no longer present. The 637 $\mathrm{nm}(\mathrm{N}-\mathrm{V})^{-}$system was generally reduced overall. The GGL sample did not have either the $(\mathrm{N}-\mathrm{V})^{0}$ or the $(\mathrm{N}-\mathrm{V})^{-}$centers. 


\section{Room-Temperature Photoluminescence}

Figure 9. Representative room-temperature photoluminescence spectra in the region from 245

to $700 \mathrm{~nm}$ are shown for GE POL diamonds

before and after HPHT

processing, as produced with three different laser sources: (A) 244 $\mathrm{nm},(B) 325 \mathrm{~nm}$, and (C) $514 / 532 \mathrm{~nm}$. See text for descriptions of the specific features.
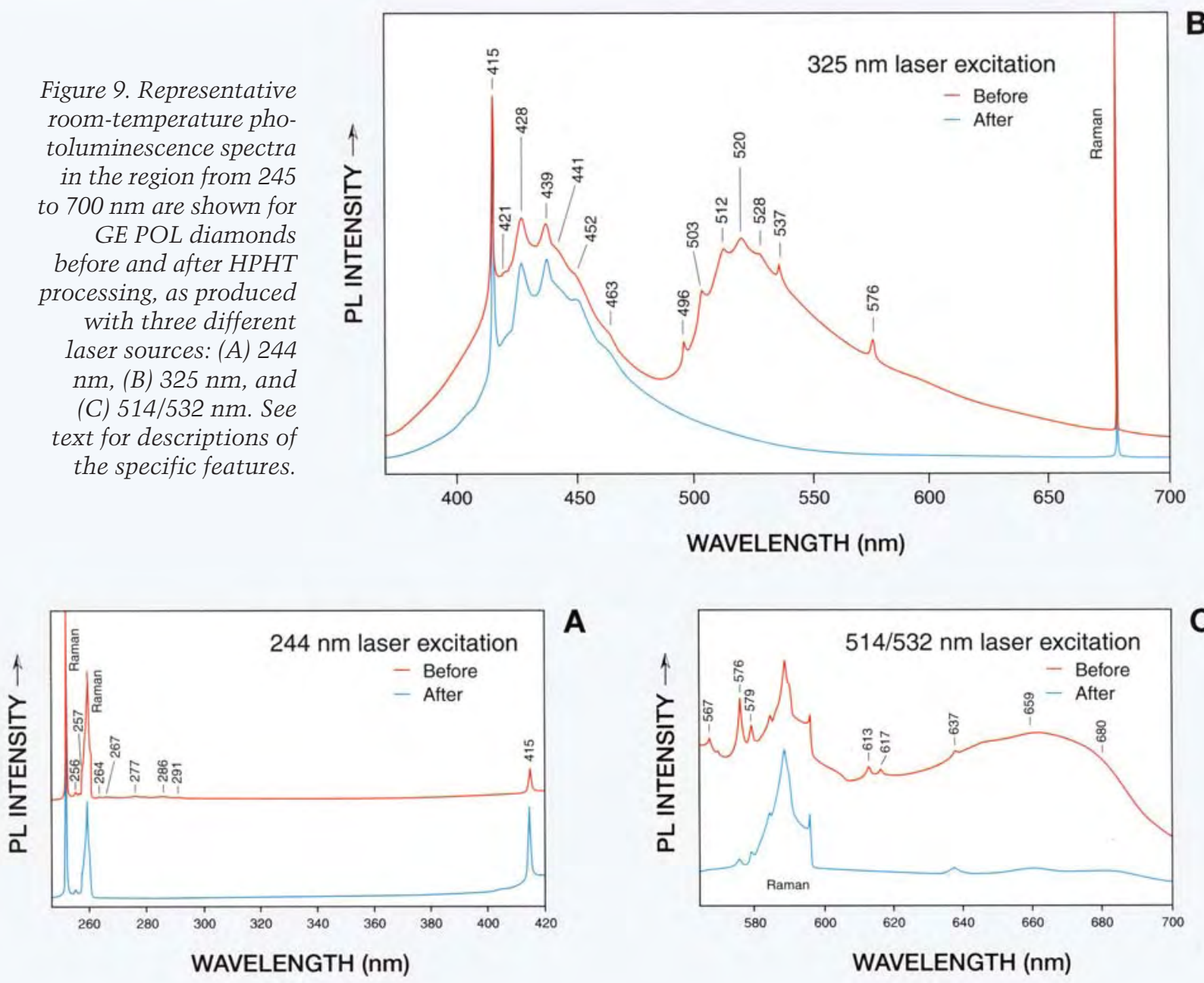

A

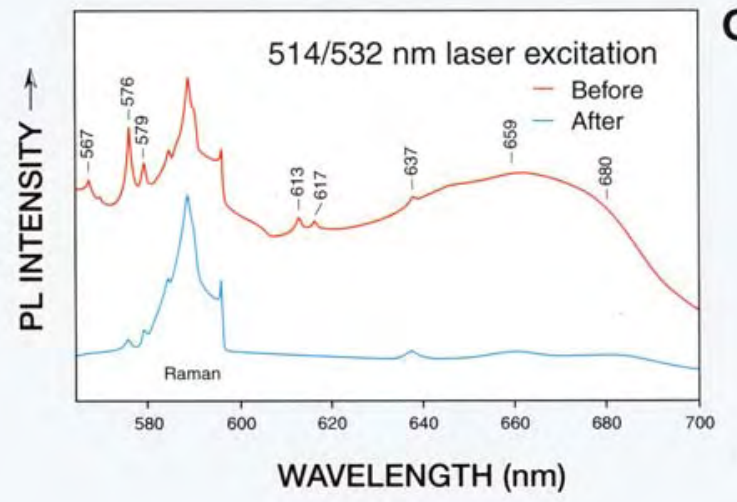

\section{Low Temperature}

Before: Again, upon cooling, improved resolution yielded additional PL features, as well as more precise peak locations (figure 10C). A series of small peaks were present at 558.8, 566.8, and $569 \mathrm{~nm}$. The two peaks at 574.8 and $575.8(\mathrm{~N}-\mathrm{V})^{0} \mathrm{~nm}$ were clearly resolved; however, with this excitation, we typically recorded $574.8>575.8$. One sample showed only the $575.8 \mathrm{~nm}$ peak, while another did not show either peak. We observed a faint to weak peak at $578.8 \mathrm{~nm}$ in all samples. There were faint, broad bands at approximately 600 and $620 \mathrm{~nm}$ in most of the samples analyzed, as well as a sharp $612.3 \mathrm{~nm}$ peak in two of them.

The $637.0 \mathrm{~nm}(\mathrm{~N}-\mathrm{V})^{-}$system was further refined to reveal sharper, more distinct bands at 637.0 (ZPL), 659, and $680 \mathrm{~nm}$. However, even at low temperature, the $637.0 \mathrm{~nm}(\mathrm{~N}-\mathrm{V})^{-}$was not present in the
GGL sample. The FWHM of the $637.0 \mathrm{~nm}$ ZPL ranged from 0.47 to $0.80 \mathrm{~nm}$, and the ratio of the 574.8/637.0 N-V peaks ranged from 1.7 to 7.7.

After: HPHT processing resulted in significant modification to this region. Again, many PL features were removed, including those at 558.8, 566.8, 569, and $578.8 \mathrm{~nm}$, and between 596 and $630 \mathrm{~nm}$. With this laser and under these conditions, the two at $574.8(\mathrm{~N}-\mathrm{V})^{0}$ and $575.8 \mathrm{~nm}$ were dramatically reduced, but still present. The relative intensity of these peaks remained approximately the same, although in a couple of samples the $575.8 \mathrm{~nm}$ peak did seem slightly more reduced. In one sample, where there was a strong $574.8 \mathrm{~nm}(\mathrm{~N}-\mathrm{V})^{0}$ peak and only a weak $575.8 \mathrm{~nm}$ peak prior to HPHT processing, the $575.8 \mathrm{~nm}$ peak was no longer evident. The $637.0 \mathrm{~nm}(\mathrm{~N}-\mathrm{V})^{-}$system was typically reduced over- 


\section{Low-Temperature Photoluminescence}

Figure 10. Because of the greater sensitivity and improved resolution provided by cryogenic cooling, these representative lowtemperature photoluminescence spectra show many features that were not recorded under room-temperature conditions. Again, the diamonds were analyzed before and after HPHT processing, using three different laser sources:

(A) $244 \mathrm{~nm},(B) 325 \mathrm{~nm}$, and $(C)$ 514/532 $\mathrm{nm}$. See text for descriptions of the specific features.
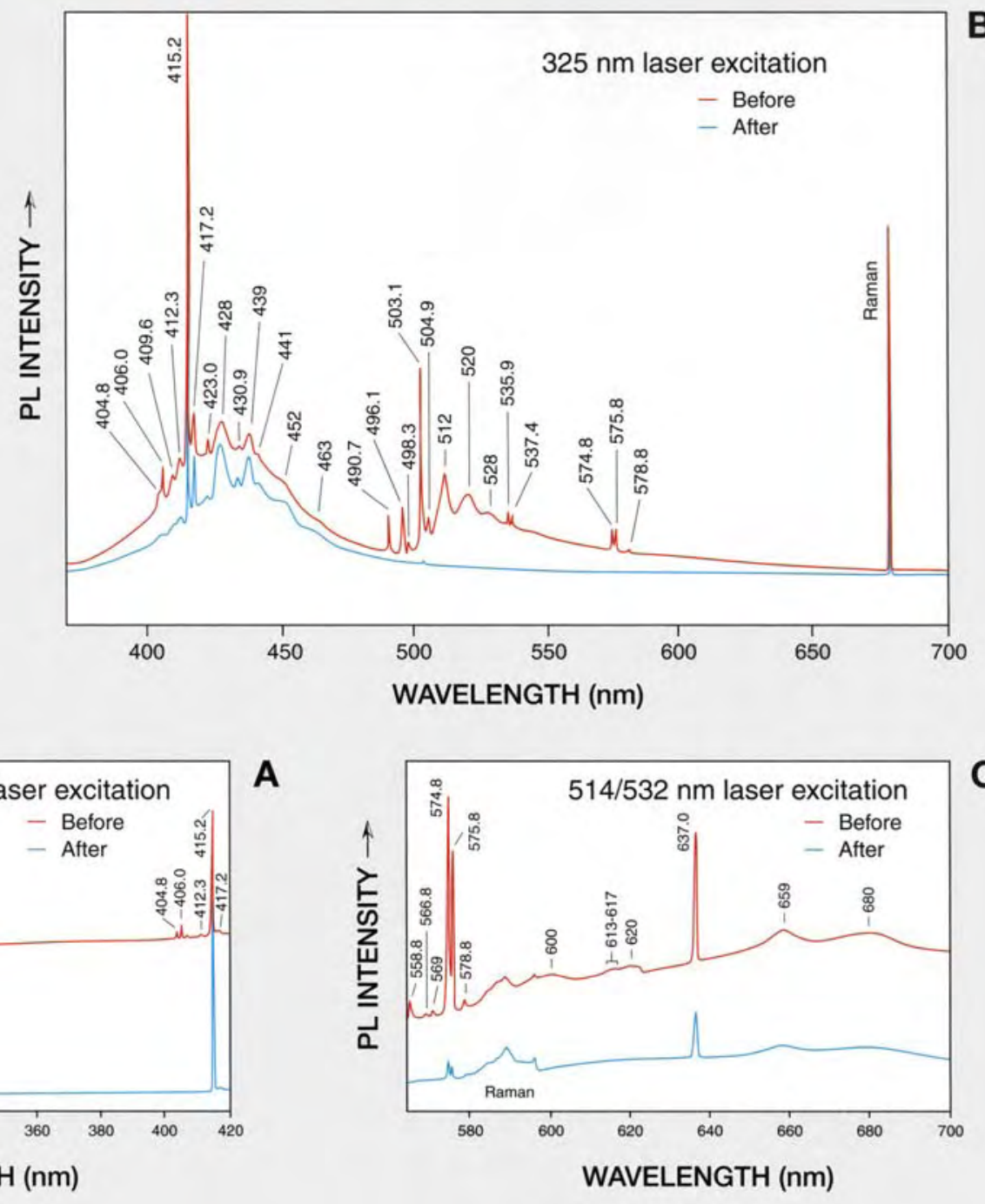

all. Even under these conditions, the GGL sample still did not show either of the N-V centers (574.8 or $637.0 \mathrm{~nm})$.

We recorded a distinct reversal in the ratio between the 574.8 and $637.0 \mathrm{~nm}$ peaks, as described by Fisher and Spits (2000). In our samples under these conditions, they ranged from 0.3 to 0.7 . The FWHM of the $637.0 \mathrm{~nm}$ peak also increased slightly to approximately 0.64 to $1.00 \mathrm{~nm}$. The slight broadening of this ZPL also occurred in all samples.

\section{RESULTS: CATHODOLUMINESCENCE AND X-RAY TOPOGRAPHY (See Box B)} Cathodoluminescence Colors

Before: We observed CL colors ranging from a chalky yellow-white of moderate intensity, to a strong blue-white. Most of the samples displayed an even texture, with no structure to the luminescence visible. However, one did reveal a slightly irregular or "cottony" overall texture, as well as a narrow "vein" that was slightly less luminescent.

After: All samples revealed a general shift in the CL colors toward blue. The strongest shift occurred with samples that changed from a moderate yellow-white to a strong blue-white after processing (figure 11). We noted no change in the distribution of the CL texture.

\section{Cathodoluminescence Phosphorescence}

All the samples revealed a rapid and steadily declining phosphorescence, which lasted approximately 1-1.5 seconds, both before and after HPHT processing. 


\section{BOX B: CATHOdOLUMINESCENCE ANDX-RAY TOPOGRAPHY AS NondestruCtive TOOLS IN Gemology}

Cathodoluminescence (CL) spectroscopy and X-ray topography can provide a great deal of information about the structure of a diamond. Because HPHT procedures may heal the dislocations and lattice defects that produce certain luminescence centers, these two methods are useful in reconstructing the processes by which the lattice is changed. Although neither method is broadly applied in gemology, CL has been used extensively in technical studies of diamonds (Panczer et al., 1996).

\section{CATHODOLUMINESCENCE}

$\mathrm{CL}$ is the emission of light from a solid surface when excited by an electron beam. Depending on the accelerating voltage (usually between 1 and $30 \mathrm{kV}$ ), the electrons penetrate about $1-3 \mu \mathrm{m}$. Some fundamental properties of minerals-such as lattice defects, impurities, and other disturbances in the crystal lattice-are represented by luminescence centers. The energy of the electron beam is transferred within a diamond by these optical centers and can give rise to distinctive CL colors and other patterns. Today, two types of CL equipment are used for gemstones to detect these optical signals.

"Cold CL" : Using flood gun optical microscopy, the luminoscope is mounted on a microscope stage. The electrons are generated in a cold cathode device. This small glass tube contains discharge gas (e.g., air, nitrogen, or helium) as well as the cathode and the anode. As soon as high tension is applied between the cathode and the anode, electrons are created. The electrons pass through the hollow anode and enter the low-evacuated $\left(10^{-2}\right.$ Torr) sample chamber. A lead-glass window in the sample compartment allows visual observation of the luminescence behavior, so the CL color, zonation, and phosphorescence can be observed. Color photomicrographs of these features can be taken at magnifications up to $125 \times$. The light emitted by the diamond is focused via the microscope objective onto a monochromator. Luminescence spectra can be recorded within a range of 380 to $1000 \mathrm{~nm}$ (compare to Ponahlo, 1996).

"Hot CL": Hot-cathode luminescence microscopy is relatively new (Götze, 1996). The CL spectrometer is attached to a scanning electron microscope (SEM), and the electrons are generated by a hot filament. The typical acceleration voltage is $15 \mathrm{kV}$, and the beam current is about $1 \mathrm{nA}$. The sample must be mounted on a special holder because of the high vacuum (about $10^{-6}$ Torr) within the sample compartment. In addition, the diamond must be coated by graphite, both so the SEM can focus on the surface of the sample (at magnifications up to about 100,000x) and to avoid charge clouds generated by the electron beam. This equipment can combine the optical and chemical analytical capabilities of the SEM-EDS system.

Because the electron beam of the SEM is focused, very small areas $(<10 \mu \mathrm{m}$ in diameter) can be analyzed. The main disadvantage is that there is no mechanism for capturing images. Luminescence spectra can be recorded between 200 and $800 \mathrm{~nm}$.

\section{X-RAY DIFFRACTION TOPOGRAPHY}

This imaging method allows visualization of defects associated with lattice distortions in a single-crystal material. It can record the spatial distribution of dislocations, growth striations, stacking faults, and even defects detectable by visual inspection, such as inclusions and mechanical damage (e.g., scratches, cracks). Although it is a nonmagnifying method with rather poor spatial resolution, it is highly sensitive to lattice strain. Because of X-ray absorption, it is usually restricted to relatively small crystals or crystal slices of limited thickness. However, diamond has a low absorption of X-rays, so samples with diameters up to $10 \mathrm{~mm}$ can be analyzed by using X-rays of appropriate wavelengths.

$\mathrm{X}$-ray topography is based on the diffraction of $\mathrm{X}$ rays by the atomic structure of the crystal. This diffraction is described by the reflection of X-rays by a set of "lattice planes" at discrete angles, according to the Bragg equation. Since there are many sets of lattice planes in a crystal (e.g., corresponding to the faces of the octahedron $\{111\}$, the cube $\{100\}$, or the rhombdodecahedron $\{110\}\}$, X-ray topographs can be recorded with different reflections: 111, 220, etc. For methods using monochromatic X-rays, such as the Lang technique, the orientation of the crystal structure with respect to the morphology of the sample must be known; only one reflection is used, providing a single topograph, and the crystal must be carefully adjusted with respect to the incident beam. See Sunagawa et al. (1998) for a short description of the Lang technique and its application to the study of faceted diamonds.

An alternative method is the old Laue technique, which uses the continuous ("white") spectrum of a conventional X-ray tube or synchrotron radiation source. This technique does not require a laborious adjustment of the crystal with respect to the incident beam; the X-ray film is simply placed behind the faceted diamond, with no pre-orientation needed. Many topographs (representing different reflections and generated by different wavelengths) are recorded on the film with a single exposure.

For more information on X-ray topography, see the reviews by Lang (1978) and Klapper (1996). 
Figure 11. The CL color of the GE $P O L$ diamonds prior to processing ranged from chalky yellow-white (left) to blue-white. After processing, all of the samples shifted in CL color to blue (right), with an increase in intensity. Photos by Johann Ponahlo.
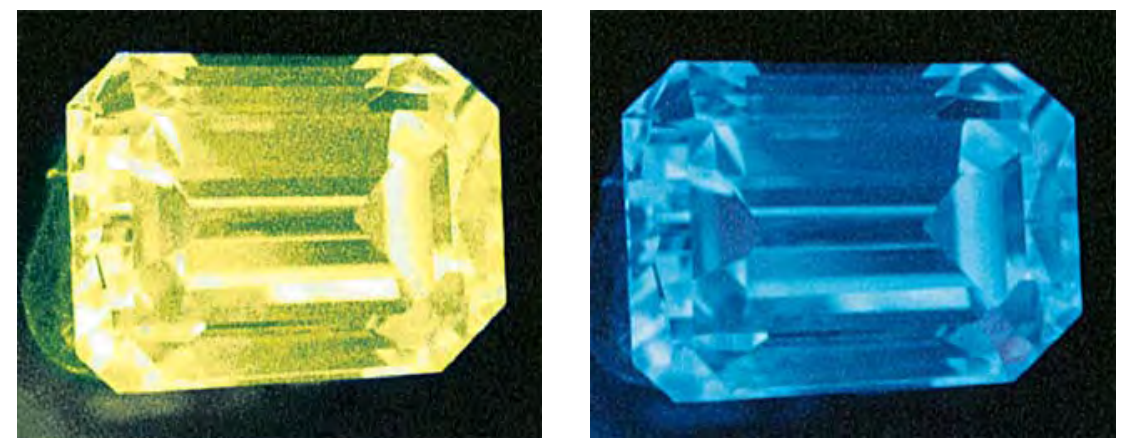

\section{Cathodoluminescence Spectroscopy}

Before: The CL spectrum of each sample was characterized by two dominant emission bands (figure 12): One band was centered at approximately 430 $\mathrm{nm}$ (in the blue region of the spectrum), and the other at about $520 \mathrm{~nm}$ (in the green region). Although much remains unknown about the mechanisms that produce these CL bands, the one centered at $430 \mathrm{~nm}$ is called the "blue" A band and has been attributed to donor-acceptor pair recombination or to dislocations (Pagel et al., 2000). In addition, it appears that this "blue" A band has been superimposed by the N3 system in the samples included in this study. The band in the green region has been attributed to $\mathrm{H} 3$ centers (Sumida et al., 1981; Jorge et al., 1983; Van Enckevort and Visser, 1990; Graham and Buseck, 1994).

It is important to mention that the "green" band revealed significantly less emission with the hot cathode as compared to the flood gun technique, because of polarizing effects of the monochromatic grid in the hot CL spectrometer. With the hot cathode apparatus, the "green" band was always significantly weaker than the "blue" band; in two samples, it was present only as a shoulder to the "blue" band. No other CL bands were observed.

After: The CL spectra were dramatically changed in all diamonds on exposure to HPHT. With the flood gun technique, it was most clearly shown that the "green" band was either dramatically reduced or completely eliminated. A similar decrease of this CL band was reported by Yang et al. (1995). This resulted in a single dominant "blue" band in the spectra for all of the samples after processing. In some diamonds, there also was a general decrease in the emission intensity of the $430 \mathrm{~nm}$ band; in others, however, there was a dramatic increase.

\section{X-Ray Topography}

Before: X-ray topographs provide a clear picture of the condition of the diamond crystal's lattice. Using the Laue technique, we identified a wide range of lattice distortion in the brown type IIa diamonds prior to HPHT enhancement (figure 13). Some samples were relatively "perfect," in that they displayed only very slight lattice imperfections, which faintly distorted the outline of the topograph, and few or no striations or changes in intensity within it. One sample, however, was heavily distorted: It revealed extreme bending of the lattice planes, as well as highly variable concentrations of lattice strain and defects. All of the other samples were intermediate between these two extremes, with the lattice planes bent to various degrees and concentrations of lattice strain and defects that ranged from homogeneous to highly irregular.

Figure 12. Before processing of the diamonds, cathodoluminescence spectra in the region from 200 to $700 \mathrm{~nm}$ revealed a pair of CL bands with maxima at approximately 430 and $520 \mathrm{~nm}$. After HPHT processing, the CL band at $520 \mathrm{~nm}$ was typically removed, although a weak shoulder remained for a couple of samples.

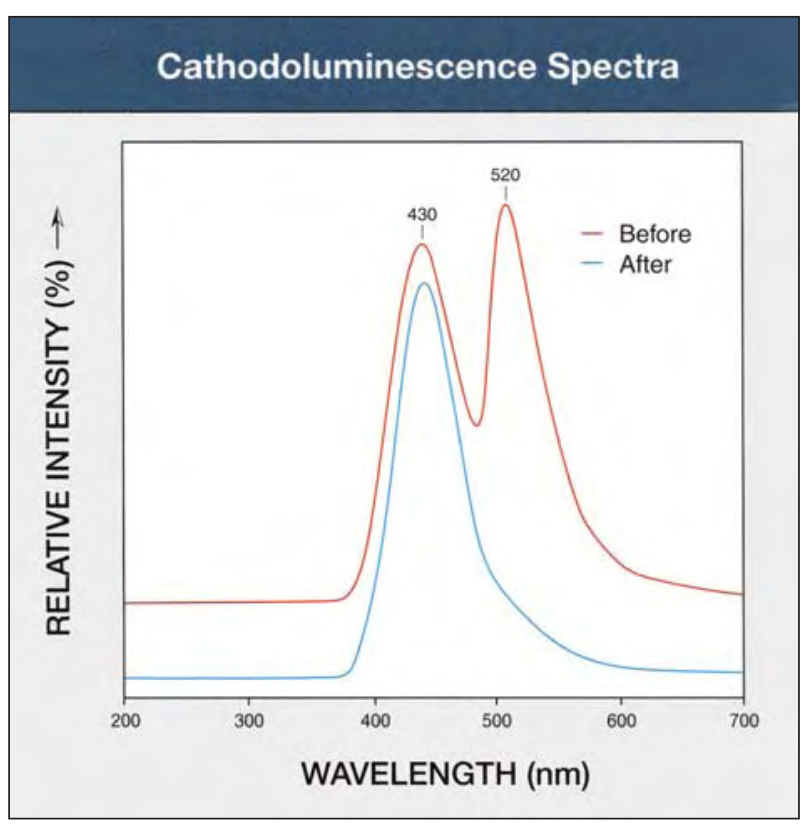



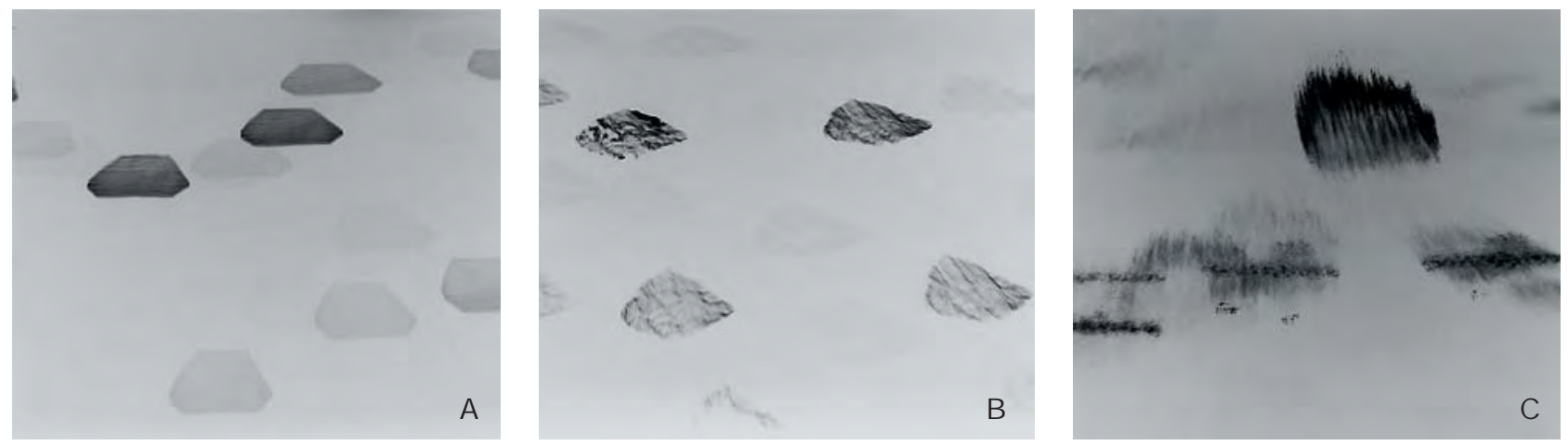

Figure 13. X-ray topography identified a broad range of crystal distortion in the diamonds prior to HPHT processing. Topograph $A$ is of a stone with very little lattice distortion, as may be seen by the geometric outline of the individual topographs and the mostly homogeneous blackening of the X-ray film. The presence of subtle striations indicates that there was also a degree of inhomogeneity in defect centers in certain regions of the crystal lattice. The diamond in topograph B exhibits an intermediate stage of lattice distortion and more prominent inhomogeneity of lattice defects, as can be seen by the uneven blackening of the X-ray film. Topograph C illustrates a diamond with more extreme lattice distortion, with lattice planes that are severely bent and dramatic fluctuations in the concentration of lattice strain and defects, which is evidenced by the amorphous outlines of the topographs and the highly irregular blackening of the X-ray film.

After: We were surprised to see no fundamental modification of the X-ray topographs after the diamonds were exposed to HPHT conditions. The relative perturbation of the crystal lattice was maintained, as was the inhomogeneity of lattice strain. Although we did detect very subtle localized changes in the intensity contrasts of lattice strain and defect concentrations in a couple of the diamonds, this was not consistently the case across the sample population.

\section{DISCUSSION}

Visual Appearance and Microscopy. We observed a number of significant changes as a result of GE's exposure of these diamonds to HPHT conditions. The most dramatic change was in color, in one case from Fancy Light brown to D (although not all stones will achieve such results).

We also gained a better understanding of what happens to various inclusions (crystals and fractures) during exposure to HPHT conditions. In the course of our ongoing research, we at GGL-like other researchers (see, e.g., Moses et al., 1999; Chalain et al., 2000)-have noted unusual-appearing inclusions in GE POL diamonds. One persistent question was whether or not the healed fractures observed in GE POL diamonds were previously "open" fractures that actually "healed" under HPHT conditions. In our sample stones, the open fractures clearly did not heal, although they did change slightly in appearance and in some cases were extended, creating an outer fringe. However, we did identify a slight degree of healing immediately surrounding an included crystal.
We did not see any fundamental changes in graining and strain before and after processing. We believe that the subtle increase in intensity of these two properties after HPHT annealing is mainly an optical effect resulting from the removal of the original brown coloration. Therefore, it appears that many of the unusual characteristics noted in other GE POL diamonds are representative of the "starting material" used rather than by-products of the HPHT process itself.

UV-Vis-NIR and IR Spectroscopy. The removal of color was a result of the reduction of the absorption continuum and of the general absorption level in the visible to ultraviolet region of the spectrum. In addition, we witnessed the development of a broad $270 \mathrm{~nm}$ band in all of the samples. The $270 \mathrm{~nm}$ band is attributed to isolated nitrogen (Dyer et al., 1965). With efficient recording techniques, this band was detectable in the samples color graded as high as D.

We did not record any changes in the IR spectra of our samples before and after treatment. Although all of the samples are type IIa, three of the GE POL diamonds showed at least faint nitrogen absorption at $1174 \mathrm{~cm}^{-1}$ caused by the B aggregate. Given sufficient IR sensitivity, evidence for the production of isolated nitrogen in the IR spectra might have been expected in at least some of the diamonds after processing. With our measuring routine, however, we did not detect the $1344 \mathrm{~cm}^{-1}$ band or even the weak, broad $1130 \mathrm{~cm}^{-1}$ band, both of which are related to isolated nitrogen atoms generated under HPHT con- 
ditions, as described by Fisher and Spits (2000). In our experience, the IR spectra of brown diamonds are occasionally accompanied by a very weak hydrogen peak at $3107 \mathrm{~cm}^{-1}$. This line is not introduced during HPHT processing.

Cathodoluminescence. In general, the CL color shifted from yellow to blue as a result of HPHT enhancement. Prior to processing, all of the diamonds had the two CL bands. After processing, only the "blue" band remained, and it was typically of higher intensity. The severe reduction or complete removal of the "green" band was most clearly witnessed with the use of the "cold" flood gun CL method. It appears to correlate with the removal of $\mathrm{H} 3$ photoluminescence as detected at room temperature with $\mathrm{He} / \mathrm{Cd}$ laser excitation.

X-Ray Topography. Most natural diamonds undergo some degree of plastic deformation subsequent to crystal growth. It has been proposed that plastic deformation of natural diamonds takes place after crystallization during cataclysm of mantle rocks (Orlov, 1977) or during eruption of the host magma to the surface (Collins et al., 2000). It is associated with birefringence along more or less parallel and even intersecting lamellar glide systems (Lang, 1967). Brown coloration in natural diamonds is generally believed to be related to such circumstances, although the exact color mechanism is still unknown (Harlow, 1998; Collins et al., 2000). If natural brown type IIa diamonds are exposed to HPHT conditions that permit plastic flow and atomic diffusion within the lattice of the diamond, it is assumed that the lattice distortion and defects are annealed and, consequently, the brown coloration is removed. For a discussion of the methods used to accomplish plastic flow and atomic diffusion in diamond, the reader is referred to Schmetzer (1999).

$\mathrm{X}$-ray topography revealed several important details relating to the distortion present in the crystal lattice and its impact on the brown coloration, strain, and graining of the diamonds we studied. The extremes we recorded in the X-ray topographs of our diamonds (ranging from relatively "perfect" to heavily distorted) were surprising because of the uniformity of color present in the individual diamonds, as well as across the sample population. "Long-range" lattice distortion (i.e., the bending of the lattice over distances of up to several millimeters), which results from plastic deformation and is recorded by this technique, may also be manifest by such visible dislocation features as graining and strain birefringence. From this work, it is evident that annealing of such long-range lattice distortion is not taking place and thus cannot be responsible for the dramatic removal of the brown coloration. Rather, our results suggest that the brown coloration is linked to submicroscopic structures on or near dislocations, which also occur as a result of plastic deformation. These may consist of vacancies and interstitials attached to a dislocation.

Consequently, we saw that HPHT processing has little if any effect on the macroscopic or longrange lattice distortion indicators (e.g., graining and strain), but it clearly has an impact on submicroscopic structures, as witnessed with PL. Although all of the isolated vacancy-related point defects discussed in this article are well understood in relation to their production of color centers, such point defects attached to a dislocation would produce optical properties very different from those produced in isolation (D. Fisher, pers. comm., 2000).

Photoluminescence. The PL studies revealed some reconfiguration in the lattice of the diamonds, by the reduction, elimination, generation, and/or movement of vacancies and interstitials, as well as of impurity elements. On the basis of this research, it is possible to propose a model for some of the events that were recorded. In particular, this very sensitive method clearly illustrated that minute amounts of nitrogen impurities are present in all of these type IIa samples, even though IR spectroscopy could not always detect them, and revealed the presence of a considerable number of point defects dispersed throughout the crystal lattice.

Our research and that of others (e.g., Collins et al., 2000; Fisher and Spits, 2000) suggests that HPHT processing releases vacancies and interstitials as the dislocations heal. The elimination of the $490.7 \mathrm{~nm}$ PL band confirms that changes are taking place at the slip traces (Collins and Woods, 1982; Collins et al., 2000). In a type IIa diamond, there is a mutual annihilation of vacancies and interstitials within the lattice. The overall effect of these changes is to reduce the brown color. In addition, HPHT processing leads to the elimination of N-V centers (through the breakup of N-V or the diffusion of interstitial carbon into the vacancy), as witnessed by the reduction of the $574.8 \mathrm{~nm}(\mathrm{~N}-\mathrm{V})^{0}$ and 637.0 $\mathrm{nm}(\mathrm{N}-\mathrm{V})^{-}$systems, as well as by the dramatic reduction of the $503.1 \mathrm{~nm} \mathrm{N-V-N} \mathrm{(H3-a} \mathrm{vacancy}$ associated with an A aggregate) luminescence and 
removal of the $496.1 \mathrm{~nm} 4 \mathrm{~N}-2 \mathrm{~V}$ (H4-a vacancy associated with a B aggregate) system. Furthermore, it is believed that the presence of vacancies and mobile nitrogen leads to the production of additional N3 centers (three nitrogen atoms surrounding a common vacancy). This was evidenced by the increase recorded in $\mathrm{N} 3$ emission after processing.

Although we did not record the sharp $1344 \mathrm{~cm}^{-1}$ or the broad $1130 \mathrm{~cm}^{-1}$ IR bands related to single substitutional nitrogen, we did detect the creation of single nitrogen by the development of the $270 \mathrm{~nm}$ broad band in the UV region of the spectrum. In their article, Fisher and Spits attributed the production of single nitrogen to the break-up of A-centers. However, from the results of our study, we attribute this to the break-up and mobilization of a vacancy associated with a single nitrogen (i.e., N-V centers; 574.8/637.0) or the diffusion of interstitial carbon into the vacancy. The reduction in the neutrally charged N-V center $(574.8 \mathrm{~nm})$ was more dramatic than that of the negatively charged $\mathrm{N}-\mathrm{V}$ center $(637.0 \mathrm{~nm})$, which resulted in a reversal of the relative intensity of $(\mathrm{N}$ $\mathrm{V})^{0} /(\mathrm{N}-\mathrm{V})^{-}$. This is consistent with the information reported by Fisher and Spits (2000). In addition, although we did not record a statistical modification of the relative intensities of the $574.8 / 575.8 \mathrm{~nm}$ peaks overall, we did note a slightly greater reduction of the $575.8 \mathrm{~nm}$ peak in some samples.

The defects responsible for several of the PL bands we recorded are not known. These include the peaks located at 406.0 and 423.0; the 498.3 and $504.9 \mathrm{~nm}$ peaks, which seemed to be related to the 496.1 (H4); the 535.9/537.4 pair; and the peaks at 558.8, 566.8, 569 , and $578.8 \mathrm{~nm}$. Therefore, we are unable at this time to discuss or explain the mechanics behind their removal during HPHT processing.

In some respects, the GGL sample did not reveal the same PL behavior as the samples from GE. We have attributed this to the fact that, based on the PL emission of the N3 system, this diamond was chemically much more "pure" than the other samples. It was not pre-selected for this condition.

The data recorded from these samples both before and after HPHT processing by GE are consistent with comparable data taken from naturalcolor brown type IIa diamonds and GE POL diamonds that have been part of a larger ongoing study being conducted by the Gübelin Gem Lab.

[Authors' note: The reconfiguration taking place within the lattice of HPHT-processed type Ia diamonds is somewhat different from that described above for type IIa diamonds, in that typically $N-V$ -
$N$ (H3 and H2) centers are being created. For a discussion of HPHT-processed type Ia diamonds, see Collins et al. (2000) and Reinitz et al. (2000).]

\section{APPLICATIONS: POTENTIAL AND LIMITATIONS}

This discussion draws from information gathered in the course of a much larger GGL research project that involves the characterization of HPHT colorenhanced type IIa diamonds and non-enhanced type IIla diamonds (the results of which will be presented in a future paper). On the basis of those data and the results obtained from this before-and-after study, we believe that we can draw several preliminary conclusions with regard to the separation of naturalcolor type Ila diamonds and GE POL stones.

First, it is important to state that thus far no single property or characteristic has been identified that will unequivocally distinguish between natural high-color type IIa diamonds and GE POL's Bellataire high-color type IIa diamonds. Rather, any such separation must rely on a combination of features and observations. A short-wave UV transparency test (see, e.g., Liddicoat, 1993) is a good method with which to begin the process, that is, to indicate that a diamond is type Ila. However, it must be kept in mind that low-nitrogen-content type Ia diamonds (in particular, type IaB's) are also short-wave UV transparent. Therefore, to firmly identify a type IIa diamond, infrared spectroscopy is necessary.

Second, although the number of high-color HPHT-processed type IIa diamonds in the marketplace may increase in the years to come, at this point there are relatively very few. Therefore, indicators that clearly establish that a diamond has not been exposed to HPHT processing are just as crucial to the separation process as characteristics that identify that a diamond has been HPHT processed.

Inclusions. The wide diversity of inclusions in diamonds is a hallmark of nature (see, e.g., Gübelin and Koivula, 1986; Roskin, 1994; Koivula, 2000). Since virtually all GE POL stones are the rare type IIa diamonds, which typically are very clean, the vast majority of inclusion features that may be seen in the broad population of diamonds are not observed in GE POL stones.

In fact, only a rather limited variety of inclusions have been noted in GE POL diamonds. These include graphitized inclusions (some with expansion halos), fractures, crystals with stress fractures, and "partially healed" fractures (see also Moses et 
al., 1999). As described above, most of these relate to the starting material, and are not a by-product of the HPHT process itself. However, although such internal features may be encountered in nonprocessed diamonds (in particular brown diamonds), they are not commonly encountered in nonprocessed high-color type IIa diamonds. Consequently, the observation of such inclusions is not proof of HPHT enhancement, but it should alert the observer that more analytical testing is necessary to confirm the origin of color.

[Authors' note: According to GE's Dr. John Casey (pers. comm., 2000), the vast majority of GE $P O L$ diamonds now being produced are in the clarity range of IF to VVS. Therefore, the inclusion features described above relate more to GE POL diamonds from earlier productions.]

Graining. A very high percentage of GE POL diamonds reveal weak to moderate internal graining, which is characteristic of the brown starting material used. Such graining has also been encountered in nonprocessed high-color type IIa diamonds, but with much less frequency.

Some types of graining that may be encountered in natural-color diamonds have not been seen in GE POL diamonds thus far. These include reflective graining planes and extensions of surface grain lines. To date, we have observed a very short surface grain line in only one GE POL diamond. It is expected that diamonds with reflective graining or extensive surface grain lines would break along that plane of structural weakness on exposure to HPHT conditions.

Strain Patterns. The anomalous birefringence exhibited by both nonprocessed high-color type IIa diamonds and GE POL diamonds is typified by weak to prominent banded and tatami extinction patterns. Therefore, these patterns are of no use in this separation. Earlier GE POL diamonds occasionally exhibited stronger, mottled strain patterns, with high-order interference colors (see, e.g., Moses et al., 1999; figure 17, left) that were unlike those seen in nonprocessed high-color type Ila diamonds. If such a strain pattern is observed in a high-color type IIa diamond, it is a good indication that the stone may have been HPHT enhanced. [Authors' note: GE's Dr. Thomas Anthony (pers. comm., 2000) reports that GE POL diamonds with high-order mottled strain were encountered only rarely in early material and are no longer produced.]
UV-Vis-NIR Absorption Spectroscopy. With the use of high-sensitivity techniques, all of the GE POL diamonds we investigated revealed absorption bands at $236 \mathrm{~nm}$ (strongest line of the N9 absorption system, related to B aggregates) and $270 \mathrm{~nm}$ (related to single substitutional nitrogen), even in the D-color stones. Although research by GGL and De Beers (D. Fisher, pers. comm., 2000) has shown that the $270 \mathrm{~nm}$ band may also occur in nonprocessed type IIa diamonds, it is apparently rare. If this band is recorded in a highcolor type Ila diamond, testing should be conducted to confirm the origin of color.

Infrared Spectroscopy. In our experience, high-color diamonds that are short-wave transparent, yet prove to have a small but obvious type Ia component in the IR, are not HPHT enhanced. High-resolution techniques (Fisher and Spits, 2000) have revealed minute traces of absorption characteristic of type $\mathrm{Ib}$ diamond (1344 and $1130 \mathrm{~cm}^{-1}$ ) in HPHT-processed diamonds. Although we did not record these bands in the GE POL diamonds we examined, if present they are a good indication of HPHT enhancement. Observation of hydrogen in a high-color type Ila diamond is not an indication of HPHT color enhancement.

If a diamond of yellow hue ( $\mathrm{H}$ color or lower) is identified as type IIa by infrared spectroscopy, this is a very strong indication that it has been HPHT processed. [Authors' note: According to Dr. John Casey (pers. comm., 2000), GE produced diamonds with such low colors only during the early stages of HPHT product development. Presently, the vast majority of GE POL diamonds are in the D through $G$ range, with the highest percentage being $D$ or $E$.]

If none of the above-mentioned features is present, IR spectroscopy is not a useful indicator.

Photoluminescence. The most consistent and significant means of distinguishing nonprocessed high-color type Ila diamonds and GE POL diamonds is through a detailed analysis of photoluminescence. Note in this section that it is very important to relate the information to the particular laser excitation used, because certain PL bands behaved slightly differently depending on the excitation. In addition, low-temperature analyses with liquid nitrogen provide the best means to resolve and evaluate the PL spectra, although room-temperature analyses with the $325 \mathrm{~nm} \mathrm{He} / \mathrm{Cd}$ laser may prove useful in some cases.

$244 \mathrm{~nm}$ Excitation. Our initial results indicate that the presence of 404.8, 406.0, 409.6, and $412.3 \mathrm{~nm}$ 
PL peaks at low temperature can provide a good indication that a high-color diamond has not been HPHT enhanced. The mechanisms responsible for the weak-to-faint PL features noted below $300 \mathrm{~nm}$ have not been identified to date, so their relevance to the distinction of GE POL diamonds is currently not clear.

$325 \mathrm{~nm}$ Excitation. A number of key features can be observed with this laser. In the region surrounding the N3 system, the presence of the 406.0 or 423.0 $\mathrm{nm}$ peaks at low temperature provides evidence that the diamond is not HPHT enhanced, whereas the $430.9 \mathrm{~nm}$ peak is a good indication of HPHT processing. Our initial results suggest that the increased intensity and narrowing of the N3 ZPL do not provide a means of separation.

In the region surrounding the $\mathrm{H} 3$ system, again the presence of a number of peaks detected at low temperature can confirm when a type IIa diamond has not been HPHT color enhanced. These include the 490.7, the $496.1(\mathrm{H} 4)$ and two associated peaks at 498.3 and $504.9 \mathrm{~nm}$, the 535.0/537.4 pair, and the $574.8(\mathrm{~N}-\mathrm{V})^{0}$ and $575.8 \mathrm{~nm}$ peaks, as well as the 578.8 $\mathrm{nm}$ PL peak. (It is important to note that some of these peaks may be recorded with the "green" Ar-ion laser after HPHT processing, so this statement relates strongly to the use of the $\mathrm{He} / \mathrm{Cd}$ laser.) A faint 503.1 $\mathrm{nm}(\mathrm{H} 3)$ ZPL may still be detected after HPHT processing; however, this N-V-N is in such low concentrations post-processing that the phonon replicas, between 510 and $530 \mathrm{~nm}$, are no longer observable.

Room-temperature PL analysis with this laser also may identify a nonprocessed high-color diamond, when PL bands are recorded at wavelengths greater than $480 \mathrm{~nm}$. These could include the 496 nm (H4), the H3 phonon replicas, and the 537, 576, and $580 \mathrm{~nm}$ PL bands, none of which was visible after HPHT processing. Note that the overall emission of the side-band structure of the $\mathrm{H} 3$ system is easier to detect when the stone is at room temperature than at low temperature.

514/532 nm Excitation. At low temperature, the presence of the $558.8,566.8$, and $569 \mathrm{~nm}$ peaks, as well as the series of PL bands between 600 and 620 $\mathrm{nm}$, is a good indication that the diamond has not received HPHT processing. The $637.0 \mathrm{~nm}(\mathrm{~N}-\mathrm{V})^{-} \mathrm{ZPL}$ has been seen in both nonprocessed and processed high-color type IIa diamonds, and so appears to be of no diagnostic value. Our research confirms the findings of De Beers (Fisher and Spits, 2000), in that we also witnessed a reversal of the ratio between the 574.8 and 637.0 peaks. A ratio of $574.8<637.0$ remains a very good, though not conclusive, indication of HPHT enhancement. The FWHM of the $637.0 \mathrm{~nm}$ line was generally greater in processed type IIa diamonds than in nonprocessed specimens that exhibited a $637.0 \mathrm{~nm} \mathrm{ZPL}$, but we did record some degree of overlap between the two distributions (as compared to, for example, Hänni et al., 2000).

Cathodoluminescence. With CL spectroscopy, we found it easier to establish that certain diamonds had not been color enhanced through HPHT processing than to identify that a diamond had been HPHT processed. In our experience, all GE POL diamonds show the single, dominant blue CL band. A small percentage of GE POL diamonds also have a very weak green CL band, which typically is present only as a shoulder to the blue CL band. Many nonprocessed high-color diamonds reveal the same type of CL spectrum; however, others have a more prominent green CL band, which has not been encountered in GE POL diamonds.

In addition, many nonprocessed high-color type IIa diamonds and all the GE POL diamonds we have examined to date display a blue CL luminescence and do not phosphoresce. Still many other nonprocessed high-color type IIa diamonds reveal yellow, pink, or white CL colors or a distinct phosphorescence; none of these reactions has been observed in GE POL diamonds.

X-ray Topography. X-ray topography revealed significant insight into the effects of plastic deformation and its role in the generation of brown color. However, our initial results indicate that it does not provide a means to distinguish GE POL diamonds. De Beers is conducting similar research with transmission electron microscopy (TEM), which is taking this type of work to an atomic level to investigate HPHT-induced modifications to dislocations and the associated changes in electronic states thought to be responsible for the observed brown absorption.

\section{CONCLUSIONS}

General Electric was the first to announce the successful HPHT synthesis of diamond in 1955. For the past two decades, GE's Superabrasives division has been exploring methods to improve the optical and mechanical properties of HPHT- and chemical vapor deposition-grown synthetic diamond, both of which have a wide variety of industrial applications. GE's 


\section{Box C: RUSSIAN HPHT-PROCESSED DiAMONDS}

General Electric is not the only company with the ability and equipment to apply HPHT techniques to remove the brown coloration in natural type Ila diamonds. De Beers has shown that they can achieve similar results in experiments aimed at establishing identification criteria (see, e.g., Fisher and Spits, 2000), and facilities in Russia and the U.S., as well as elsewhere, certainly have the apparatus and technical expertise to perform HPHT processing (see, e.g., Reinitz et al., 2000). Although the fundamental parameters of HPHT techniques will be similar from one organization to the next, the details of the individual methods will undoubtedly differ.

De Beers was aware of the potential of HPHT color enhancement 20 years ago, and as long as 10 years ago Russian colleagues had told the present authors (CPS and GB) that they were successfully lightening the color of brown diamonds (although the diamond type was not discussed). Unfortunately, we were not able to obtain actual samples at that time. Within the past year, however, we have acquired samples of HPHT-processed diamonds from sources in Russia-both type IIa colorless diamonds (figure C-1) and type Ia yellow-green diamonds.

As part of our research, we performed the same gemological and advanced analytical tests on the Russian samples as are reported in this article. Both types of samples-yellow-green and colorless-were brown before treatment, but we were only able to examine the diamonds after processing. The properties we recorded for the type Ia yellow-green samples are consistent with those described by Reinitz et al. (2000) for HPHT-enhanced yellow-green diamonds.

Although some features noted in the colorless Russian HPHT-processed diamonds do suggest that differences exist in the details of their operating conditions as compared to those used by GE, overall the properties (including photoluminescence and cathodoluminescence spectra) of the Russian stones are consistent with those of the GE POL diamonds described in this article. The senior author (CPS) examined a pink diamond that reportedly was a type IIa that had been HPHT enhanced in Russia; however, he was not given the opportunity to analyze it.

General Electric, Lazare Kaplan, and Pegasus Overseas Ltd. have been criticized since they first introduced GE POL color-enhanced diamonds. However, they must be commended for announcing this new product before they began to market it and for properly disclosing the diamonds they are processing and selling. HPHT color-enhanced diamonds coming out of Russia (and potentially elsewhere) are not being sold with the same level of conscientiousness toward the diamond trade. We know that some of these diamonds are entering the international trade through various channels without any form of proper disclosure.

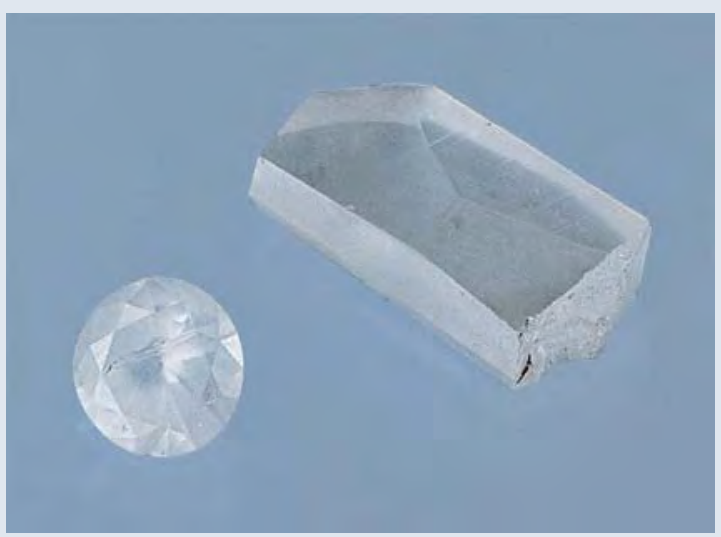

Figure C-1. These type IIa diamonds (1.53 and $0.27 \mathrm{ct}$ ) were processed in Russia using an HPHT technique similar to that used by GE. They have a frosted surface because they had not yet been repolished after processing. Photo by Phillip Hitz. research activities in this area primarily have involved the use of a high pressure/high temperature apparatus to achieve plastic flow and atomic diffusion within such materials, whereby "slippage" occurs along crystallographic directions, to remove voids and other defects. It was in the course of this research that GE happened on a means to remove the brown coloration in natural brown type IIa diamonds (J. Casey, pers. com., 2000; see, e.g., Anthony et al., 1995).

It is important to note that General Electric is not the only firm that has access to such technology. Similar experiments are being made elsewhere (see box C), and HPHT-processed diamonds from other sources may be entering the international trade without disclosure.

This study represents the first detailed analysis of actual GE POL diamonds both before and after HPHT processing by GE. Previous research on this topic was restricted to comparing the analytical details of post-processed diamonds to those of 
unrelated natural brown to colorless type IIa diamonds-in effect relying on "reverse engineering" to investigate what changes and effects were taking place as a result of the HPHT processing. Fisher and Spits (2000) described type IIa diamonds that had been HPHT-annealed as part of De Beers's research into identification techniques; however, there are undoubtedly subtle differences in the processes used by GE and De Beers. Therefore, the study of known GE-processed HPHT diamonds before and after treatment is crucial to the understanding and identification of HPHT-enhanced diamonds in general, and GE POL diamonds in particular.

Although there is still no single feature by which a GE POL diamond can be identified, on the basis of this study and our ongoing research into unprocessed high-color type IIa and GE POL diamonds, we have determined a number of features that we believe will conclusively establish that a diamond is not HPHT treated. These include a wide variety of inclusions, some types of graining, and IR spectra, as well as various photoluminescence and cathodoluminescence activities. Indicators that a diamond has been HPHT processed are provided by inclusion features and photoluminescence spectra.

In particular, this study has identified three significant regions of activity in the photoluminescence and cathodoluminescence behavior of these diamonds, between 400 and $700 \mathrm{~nm}$. These are in the spectral regions surrounding the $\mathrm{N} 3$ system (around $400 \mathrm{~nm}$ ), the $\mathrm{H} 3$ system (around $500 \mathrm{~nm}$ ), and the $\mathrm{N}-\mathrm{V}$ centers (from 550 to $650 \mathrm{~nm}$ ). To cover this spectral range, we recommend a Raman system that has been optimized for high-spectral resolution analyses at liquid nitrogen temperatures, using an $\mathrm{He} / \mathrm{Cd}$ laser $(324.98 \mathrm{~nm}$ excitation) in the UV and an Ar-ion laser (514.5 nm excitation) in the "green" region of the spectrum. (Roomtemperature conditions did reveal some usefulness with regard to the $\mathrm{H} 3$ emission; however, liquid nitro- gen temperatures are best suited for this type of analysis.) Not all of the features and mechanisms behind the observed changes are fully understood. As research continues at the Gübelin Gem Lab and elsewhere, we may find that some of these details have greater significance than is presently known.

The separation of HPHT color-enhanced type IIa diamonds is more demanding than the identification of most other forms of color alteration applied to gem-quality diamonds. It is important for the trade to understand that the application of this very sophisticated technology is progressing rapidly. Other colors that may be produced via HPHT processing of natural diamonds include yellow to yellowish green, pink, and blue (J. Casey and T. Anthony, pers. comm., 2000). Those parties involved with HPHT color enhancement will also continue to refine the techniques and conditions that they apply. Therefore, continued research is essential to guarantee that such HPHT-enhanced diamonds are fully characterized and that a means of detection is available.

Acknowledgments: The authors thank General Electric, Lazare Kaplan, and POCL for their support and cooperation, as well as for permitting documentation of the diamonds before and after HPHT enhancement. Drs. Hans-Jürgen Reich and Myriam Moreau performed Dilor LabRam Infinity Raman spectral analyses in Lille, France. Drs. Riccardo Tagliapietra, Ken Williams, and Annette Zimmerman from Renishaw PLC performed Renishaw System 1000 Raman spectral analyses. Geraint Evans, H.H. Wills Physics Laboratory, University of Bristol, U.K., assisted with the $325 \mathrm{~nm}$ Raman spectra. Prof. W. Mican and Dr. F. Brandstätter, Museum of Natural History, Vienna, Austria, are thanked for their assistance with scanning CL microscopy. The team at De Beers Diamond Trading Center, Maidenhead, provided valuable discussions and suggestions. Thomas Gübelin, president of Gübelin AG, sponsored this project.

\section{REFERENCES}

Anthony T.R., Banholzer W.F., Spiro C.L., Webb S.W., Williams B.W. (1995) Toughened Chemically Vapor Deposited Diamond. European Patent Application, open-laid No. 0671 482 A1, published September 13, 1995.

Chalain J.-P., Fritsch E., Hänni H.A. (1999) Detection of GE POL diamonds: A first stage. Revue de Gemmologie a.f.g., No. 138/139, pp. 30-33.

Chalain J.-P., Fritsch E., Hänni H.A. (2000) Detection of GE POL diamonds: A second step. Journal of Gemmology, Vol. 27, No. 2, pp. 73-78.

Collins A.T. (1982) Colour centres in diamond. Journal of Gemmology, Vol. 18, No. 1, pp. 37-75.

Collins A.T., Woods G.S. (1982) Cathodoluminescence from "giant" platelets, and of the $2.526 \mathrm{eV}$ vibronic system, in type Ia diamonds. Philosophical Magazine B, Vol. 45, No. 4, pp. 385-397.

Collins A.T. (1992) The characterisation of point defects in diamond by luminescence spectroscopy. Diamond and Related Materials, Vol. 1, No. 5-6, pp. 457-469.

Collins A.T. (1996) Characterisation of CVD and HPHT diamond. Conference Proceedings, Italian Physical Society, Vol. 52, pp. 43-57. 
Collins A.T., Kanda H., Kitawaki H. (2000) Colour changes produced in natural brown diamonds by high-pressure, high-temperature treatment. Diamond and Related Materials, Vol. 9, No. 2, pp. 113-122.

Davies G. (1977) The optical properties of diamond. In P.L. Walker, Jr. and P.A. Thrower, Eds., Chemistry and Physics of Carbon, Vol. 13, Marcel Dekker, New York, pp. 2-143.

Davies G. (1999) Current problems in diamond: Towards a quantitative understanding. Physica B, Vol. 273-274, pp. 15-23.

Dyer H.B., Raal F.A., Du Preez L., Loubser J.H.N. (1965) Optical absorption features associated with paramagnetic nitrogen in diamond. Philosophical Magazine, Vol. 11, No. 112, pp. 763-773.

Field J.E. (1992) The Properties of Natural and Synthetic Diamond. Academic Press, London, $710 \mathrm{pp}$.

Fish M.L., Comins J.D. (1997) Photoluminescence spectroscopy of synthetic diamond. Materials Science Forum, Vol. 239-241, pp. 103-106.

Fish M.L., Massler O., Reid J.A., MacGregor R., Comins J.D. (1999) The application of photoluminescence and Raman spectroscopy of synthetic diamond. Diamond and Related Materials, Vol. 8, No. 8-9, pp. 1511-1514.

Fisher D., Spits R.A. (2000) Spectroscopic evidence of GE POL HPHT-treated natural type IIa diamonds. Gems «) Gemology, Vol. 36, No. 1, pp. 42-49.

Fritsch E., Scarratt K. (1992) Natural-color nonconductive gray-toblue diamonds. Gems e) Gemology, Vol. 28, No. 1, pp. 35-42.

Götze J. (1996) Cathodoluminescence in applied geosciences: Investigation of industrial products and use of combined CL and image analysis. Abstracts of the International Conference on Cathodoluminescence and Related Techniques in Geosciences and Geomaterials, Nancy, France, pp. 61-62.

Graham R.J., Buseck P.R. (1994) Cathodoluminescence of brown diamonds as observed by transmission electron microscopy. Philosophical Magazine B, Vol. 70, No. 6, pp. 1177-1185.

Gübelin E.J., Koivula J.I. (1986) Photoatlas of Inclusions in Gemstones. ABC Edition, Zurich.

Hänni H.A., Chalain J.-P., Fritsch E. (2000) Letters: New spectral evidence for GE POL diamond detection. Gems $\oplus$ Gemology, Vol. 36, No. 2, pp. 96-97.

Harlow G.E. (1998) The Nature of Diamonds. Cambridge University Press, $278 \mathrm{pp}$.

Iakaubovskii K., Adriaenssens G.J., Nesladek M. (2000) Photochromism of vacancy-related centres in diamond. Journal of Physics-Condensed Matter, Vol. 12, No. 2, pp. 189-199.

Jackson W.E., Webb S.W. (1995) Synthetic diamond strength enhancement through high pressure/high temperature annealing. Materials Research Society Symposium Proceedings, Vol. 383, pp. 267-272.

Jorge M.I.B., Pereira M.E., Thomaz M.F., Davies G., Collins A.T. (1983) Decay times of luminescence from brown diamonds. Portugaliae Physica, Vol. 14, No. 3-4, pp. 195-210.

Klapper H. (1996) X-ray diffraction topography: Principles and techniques. In A. Authier, Ed., X-ray and Neutron Dynamical Diffraction Theory and Applications. Plenum Press, New York, pp. 137-146.

Koivula J.I. (2000) The Microworld of Diamonds. Gemworld International, Northbrook, Illinois.

Lang A.R. (1967) Causes of birefringence in diamond. Nature, Vol. 213, No. 5073, pp. 248-251.

Lang A.R. (1978) Techniques and interpretations in X-ray topography. In S. Amelinckx, R. Gevers, and J. van Landuyt, Eds., Diffraction and Imaging Techniques in Materials Science, North Holland, Amsterdam, p. 623

Lang A.R., Moore M. (1991) Cathodoluminescence and X-ray topography of HPHT diamonds. New Diamond Science and Technology, Proceedings of the 2nd International Conference, 1990, pp. 683-694.

Liddicoat R.T. Jr. (1993) Handbook of Gem Identification, 12th ed.
Gemological Institute of America, Santa Monica, CA, 364 pp.

McCormick T.L., Jackson W.E., Nemanich R.J. (1997) The characterization of strain, impurity content, and crush strength of synthetic diamond crystals. Journal of Materials Research, Vol. 12, No. 1, pp. 253-263.

Moses T.M., Shigley J.E., McClure S.F., Koivula J.I., Van Daele M (1999) Observations on GE-processed diamonds: A photographic record. Gems «) Gemology, Vol. 35, No. 3, pp. 14-22.

Orlov Y.L. (1977) The Mineralogy of the Diamond. John Wiley \& Sons, New York

Pagel M., Barbin V., Blanc P., Ohnenstetter D. (2000) Cathodoluminescence in Geosciences. Springer, Berlin.

Panczer G., Garg M., Marfunin A.S. (1996) Systems of the interacting luminescence centres in natural diamonds: Laser-induced time-resolved and CL spectroscopy. Abstracts of the International Conference on Cathodoluminescence and Related Techniques in Geosciences and Geomaterials, Nancy, France, pp. 109-110.

Ponahlo J. (1996) Cathodoluminescence: A fast, non-destructive method to distinguish between natural jadeite, dyed jadeite and dyed quartz simulants. JewelSiam, Vol. 7, No. 2, pp. 60-65.

Rapnet (1999) Pegasus Overseas Limited, a subsidiary of Lazare Kaplan International Inc. to offer diamonds with new General Electric Company process-Press Release, March 1.

Reinitz I.M., Buerki P.R., Shigley J.E., McClure S.M., Moses T.M. (2000) Identification of HPHT-treated yellow to green diamonds. Gems «) Gemology, Vol. 36, No. 2, pp. 128-137.

Roskin G.A. (1994) Photo Masters for Diamond Grading. Gemworld International Inc., Northbrook, IL.

Schmetzer K. (1999) Clues to the process used by General Electric to enhance the GE POL diamonds. Gems e) Gemology, Vol. 35, No. 4, pp. 186-190.

Sumida N., Lang A.R., Wills H.H. (1981) Cathodoluminescence and TEM studies of dislocation-rich natural diamonds. Institute of Physics Conference Series, No. 60, Section 6, pp. 319-324.

Sunagawa I., Yasuda T., Fukushima H. (1998) Fingerprinting of two diamonds cut from the same rough. Gems \&) Gemology, Vol. 34, No. 4, pp. 270-280.

Van Enckevort W.J.P., Visser E.P. (1990) Photoluminescence microtomography of diamond. Philosophical Magazine B, Vol. 62, No. 6, pp. 597-614.

Walker J. (1979) Optical absorption and luminescence in diamond. Reports on Progress in Physics, Vol. 42, pp. 1605-1659.

Webb S.W., Jackson W.E. (1995) Synthetic diamond crystal strength enhancement through annealing at $50 \mathrm{kbar}$ and $1500^{\circ} \mathrm{C}$. Journal of Materials Research, Vol. 10, No. 7, pp. 1700-1709.

Wild R.K., Evans T. (1967) Birefringence, X-ray topography and electron microscope examination of the plastic deformation of diamond. Philosophical Magazine, Vol. 15, pp. 267-279.

Wilks E.M., Wilks J. (1991) Properties and Applications of Diamond. Butterworth-Heinemann, Oxford.

Woods G.S., Collins A.T. (1986) New developments in spectroscopic methods for detecting artificially coloured diamonds. Journal of Gemmology, Vol. 20, No. 2, pp. 75-82.

Woods G.S., Lang A.R. (1975) Cathodoluminescence, optical absorption and X-ray topography studies of synthetic diamonds. Journal of Crystal Growth, Vol. 28, pp. 215-226.

Yang X.X., Barnes A.V., Albert M.M., Albridge R.G., McKinley J.T., Tolk N.H. (1995) Cathodoluminescence and photoluminescence from chemical-vapor-deposited diamond. Journal of Applied Physics, Vol. 77, No. 4, pp. 1758-1761.

Zaitsev A.M., Melnikov A.A., Denisenko A.V., Varichenko V.S. Job R., Fahrner W.R. (1996) Luminescence characterization and application of diamond. Materials Research Society Symposium Proceedings, Vol. 416, pp. 113-124.

Zaitsev A.M. (1998) Optical properties. In M.A. Prelas, G. Popovici, and L.K. Bigelow, Eds., Handbook of Industrial Diamonds and Diamond Films. Marcel Dekker Inc., New York, pp. 227-376. 